\title{
El diseño del Centro de Gobierno Latinoamericano: un analisis comparado del rol de la presidencia
}

\author{
Felipe Rosales \\ Universidad de Chile
}

\section{Resumen}

Esta investigación identifica las principales tendencias regionales asociadas al diseño institucional del Centro de Gobierno. Para esto, se consideran ocho países seleccionados en función de dos criterios: uno de máxima diferencia en la configuración institucional del Centro de Gobierno y otro de disponibilidad para acceder a la información. El desarrollo de este estudio tiene como objetivo general analizar la incidencia que posee el sistema político, el comportamiento organizacional de la presidencia y su diseño institucional sobre la configuración de rasgos comunes a nivel latinoamericano. Se evidencia un escenario caracterizado por la coexistencia de tres diseños institucionales. El primer modelo caracterizado por países que han logrado un alto nivel de formalidad institucional, conjugando baja centralidad y altos niveles de especialización (México y Brasil). El segundo modelo corresponde a países que poseen un menor grado de formalidad institucional, combinando una alta centralidad y un bajo nivel de especialización funcional (Chile, Costa Rica y El Salvador). Finalmente, el último modelo destaca por la presencia de instituciones con diversos niveles de formalidad, lo cual genera una indefinición del comportamiento institucional del Centro de Gobierno (Argentina, Ecuador y Paraguay).

Palabras clave: Centro de gobierno, sistema político, diseño institucional, comportamiento organizacional de la presidencia.

The design of the Latin American Government Center: a comparative analysis of the presidency's rol

\begin{abstract}
This research identifies the main regional trends associated with the institutional design of Government Center. We considered eight countries selected according two criteria: maximum difference in Government Center institutional settings and availability for access to information. This study analyzed the incidence of having a political system, president organizational behavoir and institutional design on configuring common features in Latin America. There were three intitutional designs. The first model characterized by countries that have achieved a high level of institutional formality, combining low centrality and high levels of expertise (Mexico and Brazil). The second model is for countries with a lower degree of institutional formality, combining high centrality and a low level of functional specialization (Chile, Costa Rica and El Salvador). Finally, the last model characterized by the presence of institutions with different levels of formality, which generate an undefined Government Center institutional behavior (Argentina, Ecuador and Paraguay).
\end{abstract}

Keywords: Central government, political system, institutional design, organizational behavior of the presidency. 


\section{Introducción}

El concepto Centro de Gobierno [CdG] hace referencia a un conjunto de instituciones que mediante un proceso de coordinación, desarrollan un complejo sistema de toma de decisiones en la esfera presidencial (Egaña y Chateau, 2011). El propósito principal del Centro de Gobierno reside en apoyar a los gobernantes durante su gestión presidencial, fortaleciendo el proceso de elaboración de políticas públicas, asegurando la definición de una estrategia de gobierno y ubicando a los líderes adecuados en los lugares correspondientes. De este modo, el análisis del conjunto de instituciones que dan forma a un Centro de Gobierno, contribuye a ampliar el conocimiento referente al rol que posee la presidencia, especialmente durante períodos de ineficiencias en el gasto, dificultad para alcanzar metas establecidas, y en última instancia, una reducción de la capacidad de gobernabilidad (Fernández y Rivera, 2012).

Las funciones desarrolladas por el Centro de Gobierno se han convertido en el nexo principal para fortalecer el proceso de formulación de políticas públicas. Este fenómeno ha renovado el interés por la reorganización del alto gobierno, reformando estructuras institucionales para reforzar el monitoreo de programas de gobierno y la correcta ejecución de la acción gubernamental (CLAD, 2011). La presencia de asuntos públicos cada vez más complejos, ha hecho ineludible el interés por fortalecer la capacidad de gobierno, entendida como el acervo de técnicas, métodos y destrezas desarrolladas al interior del Centro de Gobierno (Matus, 2007).

En Latinoamérica, la histórica presencia de sistemas presidencialistas ha complejizado el proceso de toma de decisiones, acrecentando el interés por los Centros de Gobierno. Elementos como la profundización de la democracia, han permitido visibilizar una mayor cantidad de actores durante la elaboración de políticas, integrando en ocasiones la participación de la ciudadanía para deliberar respecto a decisiones públicas (Aguilar, 2009). Asimismo, el tránsito hacia un modelo de gestión post burocrático ha permitido tecnificar el proceso de toma de decisiones, integrando mayores funciones, y roles institucionales al interior del Ejecutivo (Echebarría, 2006).

Este tipo de factores ha presionado hacia el fortalecimiento del alto gobierno, ruta emprendida en Latinoamérica a través incipientes reformas al CdG para realzar el complejo proceso de elaboración de políticas (Egaña y Chateau, 2011). Sin embargo, el trabajo investigativo desarrollado en la región se ha focalizado en la elaboración de estudios propositivos, privilegiando distintas agendas de fortalecimiento para el CdG. Este es el caso de los trabajos desarrollados por el Banco Mundial (2010) y el BID $((2013 a))$, los que establecen una serie de iniciativas que dan forma a una agenda para el fortalecimiento 
del Centro de Gobierno regional.

Las primeras investigaciones con datos empíricos sobre Centros de Gobierno provienen de los estudios desarrollados por la OCDE en la década de los 90. En este período, el principal objeto del CdG sería rodear al presidente de un staff político capaz de asesorarlo durante el proceso de toma de decisiones, mejorando así la elaboración de políticas públicas. Este interés permitiría la elaboración de estudios comparados acerca de las funciones ejecutadas por las Oficinas Presidenciales durante el proceso decisorio ${ }^{1}$ (OCDE, 1998).

Recientemente, han surgido estudios que continúan la línea conceptual elaborada por la OCDE, presentando evidencia empírica exploratoria para evaluar en qué medida los $\mathrm{CdG}$ Latinoamericanos están llevando a cabo sus funciones (BID, 2013a). Mediante un análisis de 12 países, el BID retoma el interés por una línea de investigación poco explorada en América Latina. Esto devela la importancia que posee el vértice político del gobierno, aspecto esencial para garantizar la coherencia de políticas, proporcionar cohesión institucional e incubar la innovación (BID, 2013b).

Las investigaciones latinoamericanas vinculadas a Centros de Gobierno se encuentran en estado embrionario. Previamente a lo realizado por el BID (2013a), la región ya contaba con un número limitado de estudios de caso. Los estudios existentes se han abocado al análisis de la reorganización institucional del CdG en Chile (Rehren, 1998; Rosales y Calvo, 2010; Fernández y Rivera, 2012), el estudio de la Oficina de la Presidencia en México (Méndez, 2007; López, 2010) y el análisis organizacional del CdG en Argentina (Coutinho, 2008; Martínez Nogueira, 2013). Por lo tanto, esta investigación se suma a la reciente producción analítica sobre Centro de Gobierno en América Latina, adquiriendo relevancia producto de la recopilación de antecedentes empíricos, lo que finalmente permitirá nutrir la reflexión teórica iniciada con antelación. Igualmente, es posible resaltar una relevancia social, generando relaciones de aprendizaje mutuo entre países, fenómeno que facilita el conocimiento de experiencias y problemas asociados a la pérdida en la capacidad gubernamental.

Uno de los desafíos principales que involucra el estudio del CdG latinoamericano está dado por una paradoja consistente en la similitud de funciones y

\footnotetext{
${ }^{1}$ Los estudios fueron desarrollados por el Programa de Apoyo para la Mejora de la Gobernanza y la Gestión (SIGMA), utilizando una muestra de 19 países europeos y la inclusión de EE.UU. La principal contribución del proyecto fue definir las principales funciones utilizadas en Oficinas Presidenciales para hacer frente a dificultades tales como reducción en la capacidad de gobierno.
}

diferenciación de estructuras (Aninat, 2013). Desde su establecimiento, la mayoría de los países generó diseños institucionales que contribuyeron a fortalecer la centralización del proceso decisorio (Scartascini y Tommasi, 2012). Sin embargo, las pautas institucionales y la organización interna de cada CdG provocarían diferentes capacidades de conducción, propiciando un panorama caracterizado por rediseños organizacionales sensibles a factores de contingencia y elementos situacionales (Sulbrandt, 1994; Mintzberg, 1982).

Por lo cual, esta investigación desarrollará un análisis de tendencias regionales a través de rasgos comunes presentes en un escenario caracterizado por países con una amplia diversidad de realidades político institucionales (Acuña, 2007). De esta forma, el estudio del CdG se asemeja a un tablero de puzle. En él existe una multiplicidad de piezas con diversas formas y tamaños. Estas piezas varían de país en país, y dentro de este, difieren según el mandatario (Scartascini y Tommasi, 2012). Por lo cual, para ensamblar las piezas que dan forma al diseño institucional del CdG, se vuelve fundamental analizar el comportamiento organizacional, lo cual permitirá identificar los principales puntos de convergencia, generando mayor teoría capaz de ampliar el conocimiento asociado a la configuración del Centro de Gobierno latinoamericano.

Este estudio continúa la línea conceptual desarrollada por el BID (2013a), la cual sostiene que el CdG posee funciones básicas y estructuras típicas que en conjunto prestan apoyo al presidente durante su gestión de gobierno. Así, el Centro de Gobierno es una estructura institucional de base formal que prevalece a lo largo del tiempo (Pfiffner, 2009). Esto quiere decir que los presidentes tienen la capacidad de reorganizar el CdG en función de instituciones formalmente plausibles ${ }^{2}$, las que finalmente generan un espacio diferenciado al interior del poder Ejecutivo para fortalecer el proceso de elaboración de políticas (Moe, 1990).

En vista que el CdG se localiza en el corazón del Ejecutivo, esta investigación pretende identificar las principales tendencias regionales asociadas al diseño organizacional del CdG latinoamericano. Para esto, se utilizarán ocho países seleccionados sobre la base del tipo de presidencialismo, transformando las diferencias nacionales en una ventaja comparativa al momento de establecer comportamientos organizacionales comunes al interior de la región (Acuña, 2013). Se plantea de esta manera la

\footnotetext{
${ }^{2}$ Existen estudios donde se argumenta que el Centro de Gobierno es una estructura informal (Rockman, 1987). Este tipo de análisis otorga mayor énfasis a las estructuras no institucionalizadas de un $\mathrm{CdG}$, las que impedirían identificar un diseño formal con capacidad de trascendencia temporal.
} 
pregunta: ¿Qué factores inciden en el diseño institucional del Centro de Gobierno en América Latina?, identificando los rasgos comunes que comparte la presidencia en Latinoamérica.

De esta manera, el objetivo de esta investigación es analizar la incidencia que posee el sistema político, el comportamiento organizacional de la presidencia y su diseño institucional sobre la configuración de rasgos comunes a nivel latinoamericano.

\section{Centro de Gobierno}

El CdG emerge como un conjunto de instituciones que prestan apoyo directo al presidente, participando del proceso de toma de decisiones para la elaboración de políticas públicas (BID, 2013a). La amplia gama de responsabilidades presidenciales comenzó a ser proveída por un conjunto de estructuras multifacéticas y dinámicas (Edwards y Wayne, 2010). Este hecho complejizaría el desarrollo del diseño institucional del CdG, permitiendo al presidente reorganizar las diversas estructuras y unidades funcionales al interior de la presidencia (Pfiffner, 2009).

En Latinoamérica, el CdG se encuentra altamente influenciado por el desarrollo de la Presidencia norteamericana (Lowi, 1993). Sin embargo, existen importantes diferencias institucionales producto del diseño organizacional. Las variaciones estructurales están principalmente asociadas a "disposiciones constitucionales, restricciones institucionales, prioridades políticas y tradiciones administrativas" (BID, 2013a: 10). La figura 1 sintetiza las principales estructuras que sustentan la institucionalidad del Centro de Gobierno latinoamericano.

La complejidad institucional hace posible que los procesos funcionales se ejecuten por medio de diversas estructuras, desarrollando diferentes estrategias de reorganización institucional en cada país (Banco Mundial, 2010). Por lo tanto, el contexto situacional y las necesidades políticas de cada presidente hacen del CdG un entramado institucional mutable en el tiempo, ya sea según sistemas o mandatos de gobierno. Los círculos concéntricos de la Figura 1 reflejan el diseño básico del CdG latinoamericano. La experiencia regional se caracteriza por la recurrencia de las estructuras que componen el círculo interior; la participación oficinas privadas, unidades de asesoramiento y Secretarías Generales de la Presidencia componen la base del núcleo estratégico de gobierno ${ }^{3}$ (Fernández y Rivera, 2012). En el si-

\footnotetext{
${ }^{3}$ La diferencia entre estructuras gira en torno al nivel de institucionalización. Las Secretarías Generales poseen un mayor grado de formalidad. Las unidades de asesoría son estructuras más especializadas, arraigas en ministerios o loca-
}

guiente círculo es posible apreciar instituciones que tienden a desempeñar funciones de $\mathrm{CdG}$, pero con un menor grado participación en el proceso decisional (BID, 2013a). Este es el caso de Ministerios de Interior o Secretarías de Gobernación. Por lo tanto, la configuración final del CdG latinoamericano dependerá de las instituciones que concentren funciones capaces de incidir en el proceso decisional.

\section{El Centro de Gobierno Institucional}

Las investigaciones sobre CdG han puesto el foco de atención en dos perspectivas distintas: una personal o centrada en el presidente y otra institucional o centrada en la presidencia (Krause y Cohen, 2000). La perspectiva asociada al presidente ha contribuido con estudios en materia de liderazgo, personalidad y capacidad de management presidencial (Neustadt, 1990; Lowi, 1993; Edwards, 2003). En esta línea, existen argumentos que sostienen la informalidad institucional del Centro de Gobierno puesto que el núcleo estratégico de gobierno estaría compuesto por "una organización con roles formalmente poco definidos y estructuras que desarrollan el proceso decisorio a través de un sentido común de misión" (C. y Hult, 1995: 110).

Paralelamente, existe un foco de estudio centrado en la Presidencia. El desarrollo de esta línea analítica está ligado a patrones de comportamiento organizacional y reglas del juego institucional. De esta forma, el CdG comienza a ser analizado desde enfoques administrativos y de staffing presidencial (Burke, 2000; Maley, 2013). El carácter formal de este tipo de investigaciones permite identificar incidencias sobre el diseño institucional, involucrando desde factores contextuales hasta efectos intrínsecos de estrategias presidenciales (Méndez, 2007).

Para efectos de esta investigación, se utilizará una perspectiva analítica centrada en la Presidencia Institucional. Por lo tanto, este estudio argumenta que el CdG se origina sobre un grupo de instituciones base (OCDE, 2010; Pfiffner, 2009). La literatura sobre $\mathrm{CdG}$ Institucional sostiene que el diseño estructural de la presidencia posee elementos permanentes que le otorgan una lógica propia de funcionamiento (Moe y Howell, 1999). Esto permite que el CdG quede supeditado a un diseño inicial, constituido sobre la base de reglas formales, estructuras, organizaciones y recursos capaces de resolver problemas de congruencias (Moe y Caldwell, 1994). De este modo, la adopción de un enfoque centrado en la Presidencia permite efectuar una comparación

lizadas directamente en el despacho presidencial. Por último, las secretarías privadas poseen un bajo nivel de formalidad, centralizando el proceso decisional y trabajando directamente para el presidente (Egaña y Chateau, 2011 
Figura 1: Círculos concéntricos de los Centros de Gobierno Latinoamericanos

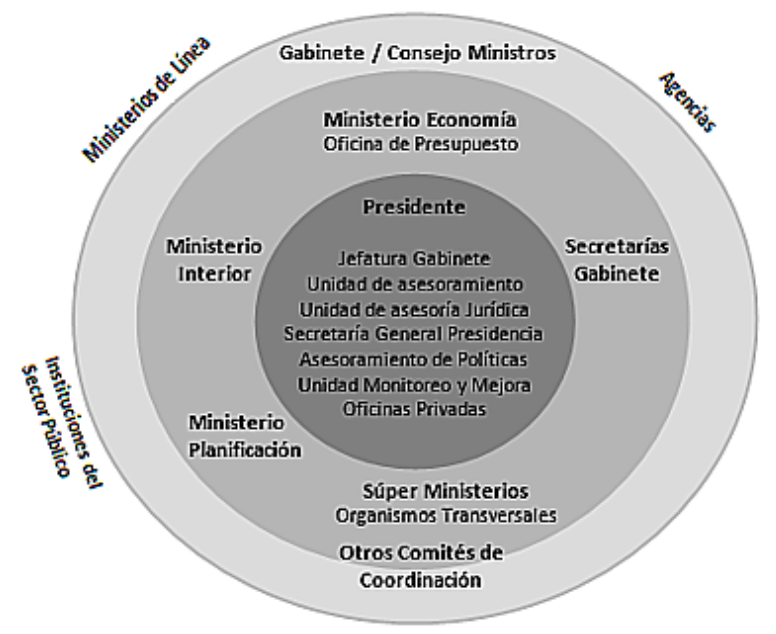

Fuente: Elaboración propia en base a BID (2013a)

sistemática sobre la base de congruencia estructural y prevalencia institucional.

Una de las corrientes que ha influenciado el análisis estructural de la Presidencia ha sido el neo institucionalismo (March y Rhodes, 1992; Peters, 2003). Sin embargo, este foco de análisis se ha centrado mayoritariamente en las relaciones entre presidente y partido de gobierno, los poderes constitucionales, los tipos de partidos políticos y los patrones de carrera legislativa (Cheibub y Limongi, 2008; Negretto, 2006). Paralelamente, confluyen otras corrientes que enfatizan el impacto de la personalidad presidencial en la configuración de la presidencia (Greeinstein, 1997; Rehren, 1998). Este fenómeno es característico en países con presidentes personalistas y poderosos.

\section{Factores institucionales sobre el Cen- tro de Gobierno}

De acuerdo a la literatura especializada, el Centro de Gobierno ha sido influenciado por tres elementos exógenos a la Presidencia. Mediante un enfoque integral, se observa un sistema complejo que interactúa en medio del contexto político, el sistema de partido y el tipo de relación con el Congreso (Gómez, 2012; Cavarozzi, 2013). Así, el entorno institucional se vuelve un elemento esencial para analizar el diseño institucional que da forma al Centro de Gobierno (Moe y Caldwell, 1994).

El aporte de diversos enfoques neo institucionalistas ha permitido el fortalecimiento de diversos estudios asociados a Presidencialismo, Presidencia y Poder Ejecutivo. En este escenario, las líneas de investigación sobre CdG se han vinculado principalmente al análisis de diseños institucionales, am- plitud de poderes presidenciales y su conexión con los principales actores partícipes del proceso de toma de decisiones para la elaboración de políticas públicas (Coutinho, 2008; Arana, 2012).

En este marco, la configuración que adopta un Centro de Gobierno no es producto de la inercia o el resultado de decisiones arbitrarias. Este engranaje institucional responde a un contexto determinado, el cual posee incentivos inherentes al entorno presidencialista (Moe y Caldwell, 1994). Por lo tanto, la Presidencia está determinada por un sistema de pautas institucionales más amplias, caracterizadas por el tipo de régimen político, el sistema electoral, la composición del Congreso y las estrategias relacionales utilizadas por el presidente (BID, 2006; Scartascini y Tommasi, 2012). Adicionalmente, existen estudios que establecen incidencias ligadas a la alternancia, la pérdida de mayorías y la capacidad de formar coaliciones (Jiménez, 2007).

Teóricamente, los estudios institucionales se han convertido en la principal fuente de conocimiento respecto al funcionamiento del Poder Ejecutivo. En efecto, el análisis de las características del sistema político ha permitido develar la organicidad que da forma a la Presidencia (Moe y Caldwell, 1994). Consecuentemente, el entorno se convierte en un elemento central para comprender la estructuración sistémica que da origen la acción institucional (Mair, 2000; Peters, 2003).

\section{Incidencia de estrategias presidencia- les}

Adicional a las teorías de incidencia exógena, existen argumentos que centran el foco de análisis en la implicancia que poseen las estrategias pre- 
sidenciales sobre el diseño organizacional del CdG (Moe y Howell, 1999). Teoréticamente, el presidente tiene la capacidad de elegir las estructuras más plausibles durante la reorganización del CdG, lo cual devalúa la importancia del control y el liderazgo en sistemas presidencialistas ${ }^{4}$.

A partir de lo dicho, existen líneas de estudio que analizan el impacto de estrategias desarrolladas por presidentes durante la reorganización de diseños institucionales de CdG (Coutinho, 2008). El objetivo de estas estrategias es contribuir a la congruencia entre los incentivos y el contexto en el que se desenvuelve el CdG. Se analizarán dos estrategias que inciden de forma endógena en la articulación del Centro de Gobierno (Moe y Caldwell, 1994).

La primera estrategia es la politización, la cual tiene el objetivo de "asegurar una mayor afinidad y lealtad a través de la designación de personal" (Moe y Howell, 1999: 149). Por lo tanto, este elemento analiza la forma en que el presidente distribuye el poder entre los partidos miembros de una coalición, utilizando criterios personalistas, técnicos, partidarios o sectoriales (Amorim Neto, 2006; Dávila, 2010). En otras palabras, la politización se asocia a la composición política del $\mathrm{CdG}$, instancia en la que el presidente tiende a seleccionar funcionarios de alta competencia (Negretto, 2006).

Los principales factores contextuales que han determinado el proceso de politización están asociados a la naturaleza política de las coaliciones de gobierno, el grado de consenso al interior de plataformas políticas y los criterios utilizados para reclutar a los principales miembros del CdG (Rehren, 1993). Estos elementos son esenciales para maximizar la preservación de coaliciones legislativas oficialistas, aspecto central para la elaboración de políticas públicas (Boeninger, 2007).

Por otra parte, el presidente cuenta con diversas estrategias de centralización, las que se materializan "imponiendo reglas de administración que constriñan el comportamiento de las agencias y construyendo organizaciones presidenciales para hacer cumplir tales reglas" (Moe y Caldwell, 1994: 38). De esta forma, el primer mandatario busca controlar estructuras que puedan localizarse fuera del alcance presidencial ${ }^{5}$. Considerando estos elementos, el

\footnotetext{
${ }^{4}$ Este argumento es desarrollado por Moe (1990) mediante un enfoque denominado "política de elección estructural". Su principal supuesto proviene de las teorías sociales, las que se integraron al institucionalismo para analizar los cambios en las estructuras de la Presidencia (Moe, 1999; Edwards \& Wayne, 2010).

${ }^{5}$ La decisión de centralizar o descentralizar es fundamental para encausar el diseño institucional del Centro de Gobierno, ya que los procesos de reorganización son influenciados por la existencia de vínculos con el gabinete, el partido
}

análisis organizacional adquiere especial relevancia para la concentración de funciones en torno al Centro de Gobierno (Mintzberg, 1982; Crozier, 1984).

El grupo tradicionalmente más importante que sustenta el proceso decisorio ha sido el de los ministerios políticos. La articulación de este grupo de ministerios permite al CdG coordinar la ejecución de políticas públicas en función de las áreas más relevantes de la administración del Estado (Arana, 2012). Sin embargo, los costos de transacción entre el presidente y su coalición, ha generado en estos ministerios políticos un efecto de doble subordinación, uno hacia el presidente y otra hacia su partido, causando la descentralización del proceso decisorio efectuado por el CdG (Waissbluth, 2008).

Los CdG institucionalizados han desarrollado estrategias conducente a una descentralización funcional, fortaleciendo la especialización de estructuras para la toma de decisiones presidenciales (Edwards y Wayne, 2010). En este panorama, las habilidades del presidente son fundamentales para el desarrollo de una gestión gubernamental capaz de resolver conflictos cruzados producto de la autonomía institucional (Lowi, 1993).

\section{El Procesos de toma de decisiones en el Centro de Gobierno}

Debido a que el CdG es la configuración de un conjunto de instituciones, su capacidad de acción se encuentra fuertemente constreñida por las estrategias de gestión utilizadas por los presidentes. Producto de esto, el análisis de los procesos internos es fundamental para comprender el tipo de interacción que se genera entre el presidente y los actores políticos durante la toma de decisiones.

De acuerdo a Neustadt (1990), la principal fuente de poder de un CdG está dada por su capacidad de gestionar el proceso de elaboración de políticas, característica que es altamente contingente a las preferencias y a al estilo del Presidente. De este modo, es posible identificar distintos modelos de gestión presidencial utilizados para liderar los procesos desarrollados al interior de un CdG. Cada modelo es capaz de alterar el proceso de elaboración de políticas, transformándose en vehículos capaces de enfrentar escenarios de conflicto político e incertidumbre (Johnson, 1974; George y Stern, 1998).

El modelo competitivo sitúa al presidente en una situación de árbitro, permitiendo que todas las unidades del CdG puedan sobreponerse. De esta forma, la duplicación de tareas genera un proceso de rivali-

oficialista o con las coaliciones de gobierno (Moe y Caldwell, 1994). 
dad, lo cual favorece el control presidencial durante los procesos decisorios y el aumento de fuentes de información. No obstante, el modelo requiere altos niveles de tiempo para administrar problemas vinculados a conflictos internos y costos de transacción (Arana, 2012; BID, 2013a).

Una segunda manera de gestionar el CdG es a través del modelo colegiado, estrategia que la que el presidente encabeza un grupo de discusión para desarrollar un proceso decisorio de carácter colectivo (Johnson, 1974). Paralelamente, la relación de unidades promueve la búsqueda grupal de soluciones, maximizando la cantidad de puntos de vista alternativos en discusión. En cuanto a las desventajas, el modelo puede llevar a que las unidades a prefieran decisiones que protejan la cohesión interna del grupo con la finalidad de lograr consensos que no tensionen el proceso decisorio (BID, 2013aa).

Por último, George y Stern (1998) presentan el modelo formal, el cual se caracteriza por la racionalización de procedimientos y canales de información. Generalmente, este tipo de modelos cuenta con un jefe de gabinete que se encarga de decidir cuál es la información que llegará al presidente. La estructuración jerárquica permite maximizar la especialización de las instituciones respecto a la recolección de información. Una de las principales desventajas es la distorsión de la información antes de llegar al mandatario y la lentitud para tomar decisiones en períodos de crisis (Arana, 2012).

A raíz de estos modelos, la literatura ha generado un debate teórico respecto a la contribución de la competencia al interior del CdG. Por una parte, Neustadt (1990) promueve la configuración de una Presidencia con incertidumbre competitiva entre los diversos actores, fenómeno que impide el aislamiento presidencial y suscita una mayor cantidad de canales de información. Sin embargo, Rockman (1987) sostiene que la ejecución requiere claridad y certidumbre. Por lo cual, el CdG no solo debe actuar para facilitar la toma de decisiones y la coordinación entre agencias, sino que también debe estar para hacer más lento el proceso decisorio, incorporando diversos puntos de vista.

El contexto condiciona fuertemente el tipo de liderazgo que un presidente puede ejercer. Los presidentes que enfrentan escenarios de incertidumbre favorecerán modelos colegiados o competitivos que promuevan mayor diversidad de información. Por otra parte, los contextos de certidumbre están asociados directamente a estilos de organización jerárquicos.

Finalmente, George (1982) plantea la posibilidad de generar un equilibrio en función de las situacio- nes. En la medida que se requiera mayor estabilidad sería más conveniente trabajar con esquemas de certidumbre coordinada. Mientras que para potenciar la búsqueda de información o la innovación en políticas sería más adecuado un modelo de incertidumbre competitiva.
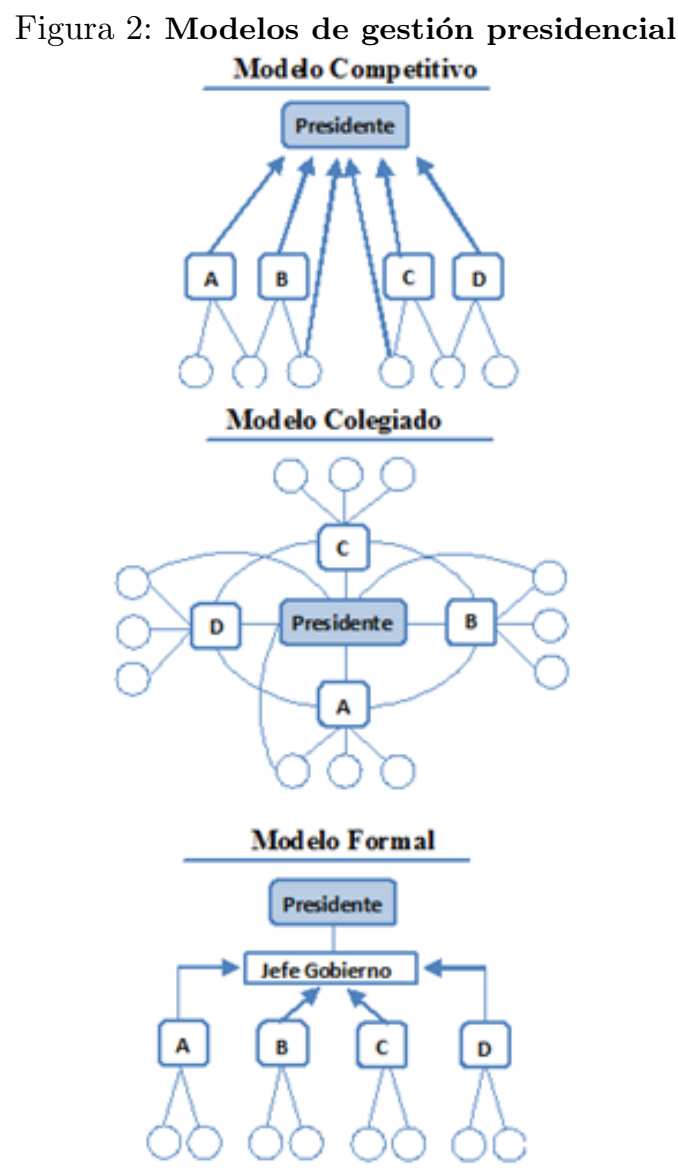

Fuente: Elaboración propia en base a BID (2013a)

\section{Metodología}

Los estudios interesados en develar cómo se configuran las instituciones que dan forma a un CdG, han evidenciado la existencia de una barrera denominada heterogeneidad institucional. Este fenómeno se caracteriza por una diferenciación que incluye regímenes, sistemas de gobierno y procesos políticos, generando dificultades al momento de comparar (Banco Mundial, 2010). Influenciado por esto, las corrientes de estudio latinoamericanas han teorizado sobre el CdG en función de marcos normativos provenientes básicamente de la experiencia en la Eurozona y el desarrollo académico propiciado por EE.UU. (Egaña y Chateau, 2011).

Producto de la diferenciación institucional, esta investigación se desarrollará mediante método com- 
parado, ya que la principal finalidad será sistematizar los rasgos comunes asociados al fenómeno de investigación (Mair, 2001). Por lo tanto, la comparación se orientará a casos, lo cual abre la posibilidad de integrar al contexto como mecanismo adicional durante el proceso de sistematización (Collier, 1999).

Para la selección de la muestra de países a analizar se consideraron dos criterios: el de máxima diferencia en la configuración institucional del CdG y el de disponibilidad para acceder a la información. Para clasificar la máxima diferencia en el estudio, se utilizó la clasificación de presidencialismo desarrollada por Henríquez y Zovatto (2009), la cual se basa en un análisis formal de los textos constitucionales organizados en un función de dos criterios centrales, el cúmulo de atribuciones presidenciales y la regulación de responsabilidades político ministeriales. El criterio de selección adoptado se torna fundamental para seleccionar países con características opuestas ya que contribuye a establecer puntos comunes en función de las diferencias institucionales y políticas de cada país (Peters, 1998).

Esta tipología diferencia los países en función de la amplitud de los poderes presidenciales. Sin embargo, existen sistemas que formalmente confieren un significativo conjunto de atribuciones de control al Congreso por sobre el presidente, pero estas difícilmente se ejercen en la práctica (Bonvecchi, 2010). Por lo tanto, cabe señalar que la clasificación utilizada establece un marco de condiciones básicas que actúa en el seno de sistemas complejos, con estructuras específicas y a la vez cambiantes según sea la matriz institucional básica del sistema político (Lanzaro, 2003).

Otro aspecto metodológico de esta investigación es la temporalidad, la cual adquiere un carácter transversal, lo que permite desarrollar un análisis del Centro de Gobierno en distintos períodos de tiempo. De esta forma, la investigación se articuló en función de los tres primeros años de los actuales gobiernos. Debido a la actualidad del análisis y a la variabilidad del calendario electoral, el inicio de algunos períodos presidenciales difieren en un rango de dos años. Este rango se amplía levemente en México y Paraguay, los cuales se rigen por el mismo criterio temporal para el período gubernamental anterior, ya que ambos países han celebrado elecciones presidenciales recientemente, contando con tan solo un año de gestión gubernamental ${ }^{6}$.

Los criterios metodológicos se ajustan a la facti-

${ }^{6}$ En México, Enrique Peña Nieto asume el 01 de diciembre del 2012. Mientras tanto, Federico Franco inicia un nuevo período presidencial en Paraguay el 22 de Junio del 2012. Por lo cual, los casos impiden un análisis igualitario respecto al rango de tiempo. bilidad de acceso a la información. Por lo tanto, la selección de países y el período de gobierno analizado tienen como finalidad contribuir a la fiabilidad de los datos. Una vez construida la matriz analítica para cada país con sus respectivos diseños institucionales de $\mathrm{CdG}$, se triangularon los datos obtenidos logrando mayor confiabilidad en el análisis. Para tales efectos, se realizaron entrevistas a informantes claves partícipes actualmente del CdG en cada uno de los países analizados.

La elaboración de todos los diseños de CdG se establecieron en función de la Matriz de Desarrollo Institucional [MDI] desarrollada por el BID. Esta herramienta se vuelve un elemento esencial para identificar las funciones básicas que ejercen las instituciones de un CdG (BID, 2013a). Para efectos de este estudio, la tabla 1 conceptualiza cuatro de las funciones básicas propuestas por el BID, las que serán utilizadas para identificar cuáles son las instituciones que integran el CdG en Latinoamérica.

En conclusión, este estudio propone un diseño institucional de $\mathrm{CdG}$ específico en cada país, el que será estructurado mediante una mandala que sintetiza las cuatro funciones básicas del CdG. Esto permitirá identificar las principales instituciones encargadas de ejercerse las actividades derivadas de la MDI elaborada por el BID. De este modo, el análisis permite identificar la estructura del Centro de Gobierno institucional, aspecto fundamental para comparar el comportamiento organizacional del CdG a nivel regional.

\section{Organización institucional y composición del Centro de Go- bierno en América Latina}

\section{El Centro de Gobierno en la adminis- tración Fernández (2011-2013)}

\section{Organización Institucional}

El diseño institucional del Centro de Gobierno argentino resalta por la multiplicidad de instituciones organizadas para ejecutar las funciones básicas del CdG. Este hecho refleja una cierta hibridez, la cual incide en los niveles intermedios de centralización decisional. De este modo, el CdG combina elementos que descentralizan el proceso de toma de decisiones e instituciones que incentivan la proximidad presidencial.

Una de las singularidades institucionales generadas en Argentina es la creación de la Jefatura de 
Tabla 1: Funciones ejercidas por las instituciones del Centro de Gobierno

\begin{tabular}{|c|c|c|}
\hline Función Básica & Actividad & Elementos Críticos \\
\hline \multirow{2}{*}{ Gestión Política } & Relaciones Institucionales & $\begin{array}{l}\text { Instituciones del CdG responsables de negociar con otros actores dando } \\
\text { apoyo al presidente para llevar a cabo su programa de gobiemo. }\end{array}$ \\
\hline & Asesoria Jurídica & $\begin{array}{l}\text { El presidente recibe asesoría juridica para determinar la legalidad de } \\
\text { propuestas de los ministerios y organismos públicos. }\end{array}$ \\
\hline \multirow{2}{*}{$\begin{array}{l}\text { Monitoreo del } \\
\text { Desempeño }\end{array}$} & $\begin{array}{l}\text { Diseño de Planes Anuales y } \\
\text { metas de gobiemo }\end{array}$ & $\begin{array}{l}\text { El CdG lidera un monitoreo continuo de los avances en las áreas prioritarias } \\
\text { de gobiemo, siguiendo la evolución de distintos indicadores. }\end{array}$ \\
\hline & $\begin{array}{l}\text { Apoyo al presidente en el } \\
\text { proceso de monitoreo }\end{array}$ & $\begin{array}{l}\text { El presidente recibe informes periódicos que le permiten supervisar el grado } \\
\text { de cumplimiento de los objetivos prioritarios de los ministerios. }\end{array}$ \\
\hline \multirow{2}{*}{$\begin{array}{l}\text { Coordinación } \\
\text { Gubernamental }\end{array}$} & Coordinación de programas: & $\begin{array}{l}\text { Los diferentes programas dentro de una misma área de política pública se } \\
\text { implementan de manera consistente y coordinada. }\end{array}$ \\
\hline & Contestabilidad de politicas: & $\begin{array}{l}\text { Las decisiones de políticas de alto nivel surgen después de considerar las } \\
\text { consultas generadas a instituciones que apoyan el proceso decisorio. }\end{array}$ \\
\hline \multirow{2}{*}{$\begin{array}{l}\text { Comunicación } \\
\text { Estratégica }\end{array}$} & $\begin{array}{l}\text { Comunicación de acciones y } \\
\text { logros gubernamentales }\end{array}$ & $\begin{array}{l}\text { Instituciones capaces de hablar en nombre del conjunto del gobiemo para } \\
\text { garantizar que la comunicación responda a una estrategia común }\end{array}$ \\
\hline & $\begin{array}{l}\text { Mecanismos de debate y } \\
\text { participación. }\end{array}$ & $\begin{array}{l}\text { El CdG garantiza que los ministerios y otros organismos escuchen la opinión } \\
\text { ciudadana, incluyendo oportunidades para debatir. }\end{array}$ \\
\hline
\end{tabular}

Fuente: Elaboración propia en base a BID (2013a)

Gabinete de Ministros ${ }^{7}$ [JGM]. Esta institución es una de las estructuras que ha incidido en la desconcentración del proceso decisorio. Su creación es producto de una reforma constitucional elaborada en 1994 por el presidente Carlos Menem. Entre sus funciones destaca la responsabilidad de mantener las relaciones del Ejecutivo con el Congreso, así como coordinar la relación entre los ministerios y jurisdicciones del Ejecutivo (Drago, 2002).

Otra de las instituciones básicas del diseño organizacional argentino es la Secretaría General Presidencial [SEGPRES]. Esta institución, estaba a cargo de una gran cantidad de actividades básicas del CdG. Sin embargo, la reforma constitucional acentuó las facultades de la JGM, lo cual implicó un desplazamiento de las labores desarrolladas por la SEGPRES argentina (Coutinho, 2008). No obstante, el ingreso de la JGM no significó una pérdida de influencia de la secretaría, ya que se convertiría en un espacio de acción multifuncional, responsabilizándose de las labores de coordinación gubernamental. Por lo tanto, la estructuración del jefe de gabinete ha contribuido al fortalecer las labores básicas del CdG, adquiriendo continuidad durante las administraciones desarrolladas por Cristina Fernández (Martínez Nogueira, 2013)

Paralelamente, instituciones como la Unidad Presidencial y las distintas Secretarías imprimen centralidad institucional a un modelo caracterizado por la multiplicidad de estructuras partícipes del CdG. Este fenómeno contribuye al constreñimiento presidencial durante el proceso decisorio ya que producto de la teoría de círculos concéntricos, estas

\footnotetext{
${ }^{7}$ La estructura interna de la Jefatura de Gabinete Ministerial ha sido variable, su papel más consistente ha sido el de apoyo político a la labor presidencial (Martínez Nogueira, 2013).
}

instituciones son cercanas al presidente.

Adicionalmente, el diseño devela la presencia de una Unidad Presidencial. Su creación data del año 2009, convirtiéndose en una estructura de gran proximidad presidencial, siendo blindada institucionalmente vía decreto para asistir directamente a la presidenta Cristina Fernández. De esta forma, la administración [2011-2013] inició con dos nuevas estructuras presidenciales: la Coordinación Gral. de Asuntos Técnicos y la Coordinación Gral. de Asuntos Políticos.

El Ministerio de Economía y Finanzas Públicas mantiene un rol central en el proceso decisorio, ya que gran parte del monitoreo y desempeño es ejecutado por esta institución. Asimismo, una parte de las atribuciones en materia económicas son lideradas por la JGM, lo cual no quita la amplia relevancia técnica del Ministerio de Economía en el diseño institucional (Martínez Nogueira, 2013).

\section{Composición Institucional del Centro de Go- bierno}

Los cargos principales del Centro de Gobierno argentino fueron asignados bajo un criterio altamente político. En función de la teoría desarrollada por Moe y Howell (1999), la amplia selección de militantes del Partido Justicialista [PJ] obedece a un sistema institucional politizado. Este tipo de estrategias busca ampliar los lazos de confianza entre el presidente y el partido oficialista, logrando un mayor grado de control sobre el proceso decisorio (Boeninger, 2007).

Paralelamente, es posible identificar rotación ministerial en puestos claves tales como la Jefatura 
de Gabinete, cargo altamente inestable en el CdG argentino. Desde inicios del año 2007 han pasado cuatro Jefes de Ministro, fenómeno que ha tendido a estabilizarse paulatinamente en el período [2011 -2013]. A diferencia de la Jefatura de Gabinete, sus secretarías internas presentan mayor estabilidad ya que las responsabilidades son parcialmente internalizadas por el titular de la Jefatura. En conclusión, la composición del Centro de Gobierno argentino devela un cierto nivel de inestabilidad, este aspecto también se presenta en el Ministerio de Economía, llegando a un total de 4 ministros en un período de seis años. Sin embargo, los primeros tres años de esta gestión permiten identificar un mayor grado de estabilidad institucional.

Una situación distinta experimentaron las Unidades presidenciales, ya que durante el período analizado, tanto Juan Carlos Mazzón como Rafael Follonier han permanecido en sus cargos. De este modo, ambas unidades generan un alto nivel de estabilidad, lo cual está relacionado a la cercanía entre las instituciones y la presidenta. Entre sus funciones básicas, cabe resaltar las facultades de apoyo al presidente en materia de negociación política y coordinación gubernamental.

\section{El Centro de Gobierno en la adminis- tración Rousseff (2011-2013)}

\section{Organización Institucional}

Durante el gobierno de Rousseff, la Casa Civil se ha transformado en el eje central de coordinación gubernamental, posicionándose como una de las principales instituciones partícipes del Centro de Gobierno brasileño (Dos Santos, 2013). El complejo entramado institucional de la Casa Civil, incentiva la desconcentración de las funciones básicas del CdG en distintas Subjefaturas que tienen por finalidad asistir directamente al presidente durante el proceso de elaboración de políticas públicas.

Igualmente, el presidente cuenta con un amplio número de secretarías directamente asociadas a funciones de gestión y comunicación gubernamental. Así, se observa un alto nivel de descentralización funcional, lo cual ha contribuido al desarrollo de una alta especialización estructural y autonomía durante el proceso decisorio.

Otra particularidad del CdG Brasileño es su capacidad de generar memoria institucional, fenómeno asociado a la institucionalización y antigüedad de las principales estructuras participes del proceso decisional. Junto a la Casa Civil, el Ministerio de Hacienda se ha convertido en una de las principales estructuras del $\mathrm{CdG}^{8}$. Esto se debe a la importancia que ha adquirido la estabilidad económica a nivel societal, convirtiéndose en un elemento central para la ciudadanía en período de elecciones presidenciales.

\section{Composición Institucional del Centro de Go- bierno}

$\mathrm{Al}$ iniciar el período presidencial, el gobierno de Rousseff se caracterizó por la presencia de un gabinete ministerial integrado por siete partidos políticos. Este rompecabezas de fuerzas políticas incluyó la distribución de puestos ministeriales y empresas estatales (Von Bulow y Lassance, 2012). Esta situación dista de la estrategia utilizada para la designación de cargos al interior del Centro de Gobierno brasileño. De este modo, el criterio utilizado para la composición institucional combinó principalmente elementos técnicos y políticos. La amplia inclusión de militantes del Partido Trabajador [PT] refleja la importancia que posee contar con el apoyo del oficialismo (Moe y Howell, 1999).

Junto a la utilización de criterios políticos, la presidenta Rousseff designó actores independientes con un alto grado de especialización técnica, aspecto ligado a la especialización funcional de las instituciones, lo que desincentiva las estrategias de politización institucional. Adicionalmente, la designación de militantes PMDB responde a estrategias para mantener la unidad al interior de la coalición de gobierno, aspecto central para fortalecer el proceso de elaboración de políticas (Boeninger, 2007).

En lo que respecta a estabilidad institucional, el gobierno de Rousseff ha generado un gran número de cambios en un corto período de tiempo, llegando a establecer un total de siete rotaciones ministeriales en tan solo once meses de gobierno. Sin embargo, la situación institucional del CdG se caracteriza un alto grado de estabilidad. Durante el período analizado [2011-2013] solo han existido tres rotaciones al interior del CdG, lo cual refleja una tendencia hacia la estabilidad institucional ${ }^{9}$.

De los tres cambios realizados en el CdG, la sa-

\footnotetext{
${ }^{8}$ Debido al sistema Federal, el Ministerio de Planificación Brasileño cumple un rol central en la coordinación gubernamental de las diversas estructuras encargadas de ejecutar las funciones básicas del CdG. De este modo, la desconcentración institucional es articulada en función de las labores realizadas por este ministerio (Dos Santos, 2013).

${ }^{9}$ La salida de Palocci se debió a una coyuntura nacional, ya que pese a contar con la confianza de Rousseff, debió renunciar a la Casa Civil luego de revelarse que su patrimonio creciera veinte veces en los últimos cuatro años. De esta forma, Hoffman llegaría a ocupar el puesto de ministra de la Casa Civil, logrando estabilidad en un puesto central para el CdG Brasileño.
} 
lida de Moreira Franco en la Secretaría de Asuntos Estratégicos y la de Luiz Nóbrega en Relaciones Institucionales se produjo a modo de enroque, siendo reasignados en otros ministerios. Finalmente, se vuelve fundamental destacar la continuidad de quince ministros partícipes de la administración presidencial anterior, fenómeno que incide en la alta estabilidad institucional.

\section{El Centro de Gobierno en la adminis- tración Piñera (2011-2013)}

\section{Organización Institucional}

Al analizar el diseño del CdG chileno, es posible identificar una fuerte centralidad del proceso decisorio. Durante el período [2011-2013] las instituciones más próximas al presidente fueron la Secretaría General de la Presidencia [SEGPRES] y la Secretaría General de Gobierno [SEGEGOB] (BID, $2013 b)$. Al poseer rango ministerial, ambas instituciones le otorgan una mayor formalidad al proceso decisorio, contribuyendo al desarrollo de funciones básicas de $\mathrm{CdG}$ tales como gestión política y comunicación. Igualmente, el Centro de Gobierno de Piñera posee un equipo de asesoría inmediata no institucionalizado, lo cual acentúa la centralidad del proceso decisorio, fortaleciendo los canales de información y el staffing para el análisis de políticas públicas coyunturales.

Una estructura central en el diseño organizacional del Centro de Gobierno chileno es el ministerio de Hacienda (Fernández y Rivera, 2012). Esta cartera ha sido esencial en la ejecución de funciones asociadas a la coordinación gubernamental y el monitoreo de políticas públicas. Asimismo, el Ministerio de Interior participa activamente de la coordinación política, fenómeno que igualmente fortalece la centralidad institucional del Centro de Gobierno.

Paralelamente, el diseño de CdG desarrollado por Piñera cuenta con un comité político, el cual constituye una instancia central de la conducción política gubernamental, dirigido por el presidente e integrado por la Secretaría General de la Presidencia, Secretaría General de Gobierno, Ministerio de Interior y Ministerio de Hacienda. En conjunto, este comité aborda los principales temas de contingencia política, transformándose en un espacio de discusión para la toma de decisiones (Fernández y Rivera, 2012).

A nivel comparado, el CdG chileno no posee especialización institucional en cada una de las funciones básicas del Centro de Gobierno. Sin embargo, estructuras tales como SEGPRES reflejan un grado de institucionalización en funciones básicas del Centro de Gobierno concentradas en unidades encargadas de ejecutar labores de gestión política, relaciones interinstitucionales y análisis de estudios coyunturales (Egaña, 2002, 2011). Por lo cual, el diseño estructural del $\mathrm{CdG}$ posee distintos tipos de instituciones encargadas de la acción gubernamental, generando un alto nivel de flexibilidad y un bajo nivel de formalidad. Este fenómeno dificulta el desarrollo de especialización funcional, memoria institucional y autonomía para la toma de decisiones fuera del núcleo central, elementos que hacen de este Centro de Gobierno una estructura semi institucionalizada.

\section{Composición Institucional del Centro de Go- bierno}

Durante el inicio de su administración, el presidente Piñera seleccionó un equipo de trabajo caracterizado por personajes vinculados al mundo académico y empresarial. En esta línea, la estrategia utilizada para la designación de cargos se generó sobre la base de criterios técnicos y políticos (Fernández y Rivera, 2012). Inicialmente, la selección de técnicos primó por sobre la politización del Centro de Gobierno (BID, 2013b). De esta forma, el CdG se constituyó sobre la base de un equipo de solidez técnica, lo cual sería combinado con militantes de Renovación Nacional [RN] y del partido Unión Demócrata Independiente [UDI], generando una estrategia capaz de integrar a los partidos que sustentaban la coalición de gobierno.

Es posible identificar una alta estabilidad en carteras como Hacienda o Secretaría General de la Presidencia. Ambos ministerios permanecieron estables durante los tres primeros años de gobierno. Igualmente, tanto Larroulet en SEGPRES como Larraín en Hacienda provenían del mundo académico, convirtiéndose en miembros del círculo íntimo de Piñera antes de ser electo presidente. Por otra parte, el equipo de asesores fue liderado por María Luisa Brahm, con la que mantenía una relación de trabajo por largos años (Fernández y Rivera, 2012).

\section{El Centro de Gobierno en la adminis- tración Chinchilla (2010-2012)}

\section{Organización Institucional}

El CdG costarricense es organizado mediante una amplia diversidad de instituciones encargadas de ejercer las funciones básicas de CdG. El CdG está configurado por cuatro tipos de instituciones: Oficinas Presidenciales, Consejos Políticos, Ministerios y staff de asesoría no institucionalizada. En conjunto, 
es posible apreciar un diseño que centraliza el proceso decisorio en torno al presidente. Esto se debe a la gran cantidad de oficinas con rango de secretaría al interior del círculo más cercano a la presidencia. De acuerdo a la teoría de círculos concéntricos, este tipo de estructuras poseen un mayor constreñimiento institucional (BID, 2013a).

La amplia diversidad de instituciones contribuye al fortalecimiento de la especialización funcional. Sin embargo, la participación de estructuras semi formales como el Staff de Asesoría Presidencial o el Grupo de Expertos permanente contribuye a la informalidad de la tecnificación de los organismos encargados de ejercer las funciones básicas de un CdG (C. y Hult, 1995). De este modo, el diseño costarricense favorece elementos como la flexibilidad y adaptabilidad organizacional, permitiendo al presidente un mayor grado de personificación al momento de reorganizar las instituciones.

El Staff de asesoría destaca principalmente por ser una estructura no institucionalizada encargada de funciones relacionadas al apoyo para la toma de decisiones; el análisis de coyuntura, comunicación estratégica y coordinación gubernamental ${ }^{10}$. Igualmente, el comité político y el grupo de expertos responden a una lógica semi formal. Este último está compuesto por un equipo permanente de seis tecnócratas altamente calificados para proponer a la Presidenta distintas propuestas abocadas a fortalecer la calidad del sistema democrático y el funcionamiento institucional.

Paralelamente, el CdG diseñado en la administración Chinchilla cuenta la participación del Ministerio Presidencial, Ministerio de Hacienda y el Ministerio de Planificación. En conjunto estas instituciones se convierten en el soporte del CdG institucional, formando parte de un diseño base que sustenta las principales funciones desarrolladas por todo CdG (Pfiffner, 2009). Adicionalmente, la presidenta Chinchilla ha establecido la creación del Ministerio de Comunicación, éste fue creado recientemente para fortalecer labores vinculadas a la comunicación política.

\section{Composición Institucional del Centro de Go- bierno}

Durante los dos primeros años de gobierno, 15 de los 21 ministros que iniciaron la gestión presidencial de Chinchilla dejaron sus carteras por diferentes motivos. Uno de los cambios centrales fue la salida de Marco Varga, quien renunció a su cargo

\footnotetext{
${ }^{10}$ Las funciones del staff asesor se encuentran plasmadas en Murillo (2008) quién corrobora la utilización de asesorías presidenciales no institucionalizadas.
}

producto de una pérdida de influencia del Ministerio al interior del Centro de Gobierno.

Por otra parte, la composición del CdG diseñado por Chinchilla ha contado con una alta politización estructural. Mediante criterios de inclusión partidaria, la presidenta asignó una gran cantidad de militantes del PLN, mecanismo que fortalece los vínculos con el partido oficialista (Moe y Howell, 1999; Boeninger, 2007). Asimismo, la designación de militantes del PUC se vuelve esencial para estrechar los vínculos estratégicos con partidos de coalición (Moe y Caldwell, 1994). En suma, pese a estar conformado por personas con amplia experiencia política, el CdG costarricense ha sufrido una rotación mayor a la de otros gobiernos. Asimismo, las principales rotaciones han sucedido en un contexto de denuncias de corrupción y mal manejo político que ha terminado por deslegitimar la labor desarrollada por el Ejecutivo en su conjunto (Gómez y Villareal, 2013).

\section{El Centro de Gobierno en la adminis- tración Correa (2009-2011)}

\section{Organización Institucional}

La constante restructuración del Poder Ejecutivo se ha convertido en uno de los principales obstáculos para el análisis del CdG Ecuatoriano. La reorganización de funciones ha potenciado la participación de nuevas instituciones, mientras que otras se han alejado del CdG o simplemente han desaparecido. Este es el caso de estructuras como el Ministerio de Coordinación de la Política creado el 2007, institucionalidad que participó directamente del CdG y que hoy ha transferido sus potestades a la Secretaría Nacional de Gestión de la Política.

Es posible identificar un CdG caracterizado por una amplia red de instituciones. Cabe señalar que el diseño institucional está estructurado en función del período [2009-2011], ya que previo a la reforma constitucional algunas instituciones fueron desplazadas fueras del proceso decisional (Muñoz, 2012). La alta frecuencia en la reorganización institucional refleja el aprendizaje y la indeterminación ${ }^{11}$ de estrategias vinculadas a la centralización o desconcentración del proceso decisorio.

Pese a la reconfiguración del Poder Ejecutivo, la Secretaría Particular ha permanecido como una de las estructuras más próximas al despacho presidencial. Desde su creación, esta estructura se ha dedicado a fortalecer la gestión político estratégica

\footnotetext{
${ }^{11}$ Mientras los ministerios coordinadores se encargan de la descentralización de las funciones básicas del CdG, secretarías como SENAPLADES se encarga de centralizar las decisiones, respondiendo directamente al presidente Correa.
} 
del Presidente, a través de unidades dedicadas a la coordinación de agenda estratégica y el control de gestión de compromisos presidenciales (Acuerdo $\left.\mathrm{N}^{\circ} 350,2010\right)$. De este modo, la combinación de insituciones fortalece la especialización funcional.

Una particularidad de este CdG es la activa participación de la Secretaría Nacional de Planificación y Desarrollo [SENAPLADES], encargada de asistir y asesor directamente al presidente en materia de diseño, seguimiento y evaluación de políticas. En este contexto, SENAPLADES se ha posicionado como una estuctura clave en la actual configuración del CdG ecuatoriano, remplazando las funciones de gestión política realizadas anteriormente por la Secretaría de la Presidencia (Muñoz, 2012).

\section{Composición Institucional del Centro de Go- bierno}

Es posible identificar un CdG compuesto principalmente por militantes del partido Alianza PAÍS. Adicionalmente, se utilizaron criterios técnicos para la asignación de ciertos puestos específicos. De esta forma, la estrategia utilizada por Correa responde a un alto nivel de politización, integrando únicamente a militantes del partido oficialista. Este fenómeno es matizado por unos pocos actores tecnocráticos, ocupando cargos ligados a su área de experticia.

En materia de estabilidad, solamente dos instituciones se mantuvieron sin rotación ${ }^{12}$, lo cual refleja un alto grado de inestabilidad interna. Durante el período [2007 -2010] el Presidente Correa hizo 74 nombramientos en 27 ministerios, lo cual corrobora la alta inestabilidad en el equipo de gobierno ( $\mathrm{Pa}-$ chano, 2010). Por ende, algunos Ministerios Coordinadores ${ }^{13}$ como Sectores Estratégicos y de la Política experimentaron una rotación por cada año analizado.

\footnotetext{
${ }^{12}$ Los hermanos Alvarado fueron los únicos actores que se mantuvieron en el cargo durante el período analizado. Asimismo, resulta esencial destacar la estabilidad de Vinicio Alvarado en la Secretaría de Administración Públicas desde el 2006 (Freidenberg, 2012).

${ }^{13} \mathrm{El}$ Poder Ejecutivo cuenta con 8 Ministerios Coordinadores, de los cuales Coordinación de Sectores Estratégicos y Coordinación de la política poseen funciones inherentes a las labores desarrolladas por el $\mathrm{CdG}$, logrando mayores niveles de descentralización.
}

\section{El Centro de Gobierno en la adminis- tración Funes (2009-2011)}

\section{Organización Institucional}

El diseño del CdG salvadoreño se caracteriza por la activa participación de secretarías localizadas al interior de la Presidencia, contribuyendo a la centralización del proceso decisorio. Una singularidad institucional del caso salvadoreño es la ausencia de un Ministerio Presidencial, estructura básica del CdG latinoamericano (BID, 2013aa). Esto ha generado una amplia participación de la Secretaría Técnica, Secretaría de Asuntos Estratégicos y la Secretaría de Comunicación. En conjunto, estas secretarías forman la estructura base del CdG durante el inicio de la administración Funes, ejecutando las principales funciones básicas desarrolladas por el Centro de Gobierno regional.

En la práctica, la organización institucional se encuentra altamente centralizada ya que todas las secretarías responden directamente al presidente. Igualmente, se observa la configuración de un staff de asesoría no institucionalizado, fenómeno que fortalece el proceso decisorio presidencial, constriñendo las labores desarrolladas por organismos más alejados a la presidencia (C. y Hult, 1995). Las labores del staff salvadoreño están directamente vinculadas a labores de gestión política y coordinación gubernamental, lo cual contribuye a personalizar el diseño institucional del CdG.

Por último, la organización institucional no posee estructuras institucionalizadas para cada una de las funciones básicas desarrolladas por el CdG. Este fenómeno disminuye los niveles de especialización funcional del diseño salvadoreño. No obstante, el CdG cuenta con la participación del Ministerio de Hacienda, otorgando mayor tecnicidad a labores asociadas a la coordinación y monitoreo del desempeño. De este modo, el rol del Ministerio de Hacienda es fundamental para suplir la ausencia de estructuras tales como Oficinas Presidenciales o Ministerios Generales de la Presidencia.

\section{Composición Institucional del Centro de Go- bierno}

En un plano interno, el CdG salvadoreño está compuesto principalmente por actores independientes, lo cual refleja la estrategia utilizada por Funes para despolitizar la principal estructura del Ejecutivo. En lo que respecta a criterios de selección, el equipo partícipe del $\mathrm{CdG}$ posee un alto perfil académico y una baja experiencia política, lo cual es asimilable al perfil que caracteriza al propio pre- 
sidente Funes ${ }^{14}$.

La Secretaría de Asuntos Estratégicos es la única institución partícipe del $\mathrm{CdG}$ liderada por un militante del FMLN, lo cual corrobora la estrategia de despolitización desarrollada por Mauricio Funes, Adicionalmente, es posible señalar los lazos de amistad existentes entre Hasbún [FMLNN] y el primer mandatario, aspecto que permitiría sostener los vínculos del partido oficialista con el presidente (Reverse, 2009).

En lo que respecta a rotación, el CdG diseñado por Funes presenta un alto nivel de estabilidad. Durante los tres primeros años, sólo Dionisio Machuca abandonó su cargo voluntariamente en la Secretaría de Asuntos Legislativos. Posteriormente, el presidente Funes optaría por mantener un criterio de despolitización institucional, asignando en el mismo cargo a Ricardo Marroquín, actor cercano al mundo técnico y privado. De este modo, el principal criterio de selección está asociado a la tecnocracia de los cargos.

Por último, se vuelve central destacar la continuidad del Ministerio de Hacienda, cartera liderada por Mario Cáceres, un experimentado asesor financiero del sector privado y altamente calificado a nivel académico. De este modo, el CdG salvadoreño responde a una lógica de cercanía con experiencias técnicas y académicas, lo cual ha generado una amplia variedad de críticas por parte del FMLN.

\section{El Centro de Gobierno en la adminis- tración Calderón (2007-2009)}

\section{Organización Institucional}

Durante el primer año del sexenio presidencial de Felipe Calderón, el CdG adoptó la configuración de un esquema altamente centralizado. Esta transformación estructural inició el 2006 mediante la creación de la Oficina de la Presidencia (OPP), encargada de coordinar las distintas unidades administrativas de asesoría y apoyo técnico al interior de la Presidencia ${ }^{15}$ (López, 2010)

Dos años después, el presidente optó por volver a reformar el CdG, sacando atribuciones a la OPP

\footnotetext{
${ }^{14} \mathrm{Al}$ no provenir de las filas del FMNL, el presidente Funes debió enfrentar múltiples dificultades para lograr el apoyo del partido oficialista. De este modo, el perfil de Mauricio Funes está directamente asociado al mundo académico (Reverse, 2009).

${ }^{15} \mathrm{Al}$ iniciar el sexenio presidencial, Felipe Calderón eliminaría dos Oficinas Presidenciales; la Oficina para la Innovación Gubernamental y la Oficina para políticas públicas, dejando un total de cinco estructuras.
}

para remitirlas a la Secretaría Particular ${ }^{16}$ y a la Coordinación de Comunicación Social. Por lo cual, estas estructuras salen de la OPP y se convierten en entes paritarios respecto a la jerarquía adquirida por la Oficina Presidencial. Bajo este marco, el CdG transitó desde una organización con tintes centralistas hacia una desconcentrada tendiente a la dispersión (López, 2010).

Por otra parte, la participación de la Secretaría de Gobernación y Secretaría de Hacienda reflejarían la baja centralización del proceso decisorio presidencial. Al poseer rango ministerial, ambas estructuras operan fuera del control directo del presidente (Lajous, 2000). Este fenómeno se debe a la especialización de funciones, generando estructuras que sectorializan labores propias de un Centro de Gobierno (Flores, 2007).

Una de las particularidades del CdG mexicano es la versatilidad de la Secretaría de Gobernación, estructura que cumple funciones de enlace legislativo, acuerdos políticos y actividades de comunicación con la ciudadanía, labores que generalmente se encuentran arraigadas en Secretarías Presidenciales (López, 2010). Asimismo, el CdG posee gabinetes especializados creados por el presidente, convirtiéndose en instancias de coordinación al interior del Ejecutivo lideradas por un Secretario Técnico para dar seguimiento a un sector específico de política pública.

\section{Composición Institucional del Centro de Go- bierno}

En cuanto a la composición interna del CdG, se observa un cierto nivel de estabilidad en la mayoría de las estructuras institucionales. Los principales cargos en los que ha existido continuidad son la Secretaría Particular y las coordinaciones de asesores y comunicación. Sin embargo, la OPP presenta un alto nivel de inestabilidad, llegando a contar con un Jefe de OPP por año.

La inestabilidad de la Secretaría de Gobernación requiere un análisis particular ya que a excepción de Juan Mouriño, el resto de los secretarios ha salido del cargo para ocupar otro opuesto de importancia a nivel gubernamental. De esta forma, muchos de los cambios generados por el Presidente Calderón responden a un enroque político entre distintos actores de confianza (Temkin y Salazar, 2012).

Sin embargo, la inestabilidad institucional se ve

\footnotetext{
${ }^{16}$ Fuera del dominio de la OPP, la Secretaría Particular adquiriría un mayor protagonismo al interior del CdG, convirtiéndose en una de las estructuras más próximas al jefe de gobierno, lo cual devela su fortalecimiento a nivel funcional (López, 2010).
} 
reflejada a nivel de gabinete, ya que de un total de 18 secretarios que iniciaron el período [2007-2009], seis de mantuvieron en sus cargos, realizándose un total de 26 rotaciones de gabinete en un período de cinco años de gobierno, lo cual convierte a la administración Calderón en una de las más inestables en las últimas décadas.

\section{El Centro de Gobierno en la adminis- tración Lugo (2008-2010)}

\section{Organización Institucional}

Producto del constante debilitamiento del Poder Ejecutivo, una de las medidas iniciales del Presidente Lugo fue decretar la reestructuración del gabinete civil de la Presidencia. Este órgano institucional está facultado para asistir, asesorar y coordinar la gestión del Titular del Poder Ejecutivo en el proceso de definición, instalación, comunicación y seguimiento de políticas públicas (Decreto $\mathrm{N}^{\circ} 8.800$ ).

De esta forma, los pilares del CdG en el que se refugió el Presidente Lugo fueron la Secretaría General y el Gabinete Civil. Bajo una mirada institucional, se observa que la organización institucional del CdG paraguayo. El Gabinete Civil es el órgano más próximo al primer mandatario en materia de asesoría directa. Adicionalmente, el rol de la Secretaría General es esencial para la ejecución de funciones básicas del $\mathrm{CdG}$ tales como gestión política y coordinación gubernamental. De forma conjunta, estos organismos son la base de la reorganización institucional efectuada durante la gestión desarrollada en el período [2008-2009] $]^{17}$.

Asimismo, el CdG está configurado por la participación de los ministerios de Hacienda e Interior, órganos que a diferencia de las secretarías, tienen responsabilidad de velar por el funcionamiento de políticas sectoriales, transformándose en actores esenciales para la descentralización del proceso de toma de decisiones. Sin embargo, las funciones de coherencia, comunicación y coordinación se encuentran fuertemente arraigadas en la Secretaría General, lo cual responde a mecanismos de centralización institucional, diseñados para fortalecer el control presidencial.

\footnotetext{
${ }^{17}$ La profunda reorganización del diseño institucional desarrollado por Fernando Lugo devela la presencia de un diseño en proceso de ajuste. Mientras algunas instituciones incentivan la centralización [Gabinete Civil], existen otras que contribuyen a la autonomía del proceso decisorio, tales como los Ministerios de Hacienda y Ministerio de Interior.
}

\section{Composición Institucional del Centro de Go- bierno}

En lo que respecta a los primeros tres años de gobierno, la composición del CdG se estructuró en función de criterios técnicos. De este modo, la estrategia de politización es mínima en la asignación de cargos institucionales. Durante esta administración, Miguel Ángel López se encargó de presidir la Secretaría General y el Gabinete Civil. El nexo existente entre Lugo y López fortalece la integración de actores políticos tales como los del Movimiento Tekojoja [MT]. Sin embargo, la fuerte lógica tecnocrática incidiría en la baja participación de actores políticos al interior del CdG institucional.

El Presidente Lugo optó por componer su CdG en función del merito, en desmedro de los clásicos favores políticos (Nickson, 2009). Por lo tanto, el perfil de la mayoría de los miembros responde a cargos de alta tecnicidad. Este es el caso del Ministerio de Economía y el Ministerio de Planificación, los cuales serían ocupados por personalidades independientes [IND] que gozan de un respeto producto de un largo desempeño en el mundo académico y profesional.

En términos generales, de un total de once ministerios, solo cuatro de ellos fueron ocupados por militantes del PLRA, lo cual evidencia la poca politización del Centro de Gobierno institucional. Este fenómeno es central para comprender la inestabilidad de la [APC], ya que mientras el Presidente actuó como líder de las fuerzas de izquierdas aglutinadas en el Frente Guazú, dejó el liderazgo del PRLA al arbitrio de sus facciones internas (Abente, 2012). El quiebre al interior de la coalición oficialista se vería reflejado en rotaciones ministeriales tales como la de Rafael Filizzola $[\mathrm{PDP}]^{18}$ quien debió salir por órdenes presidenciales para ser remplazado por un actor de perfil técnico.

\section{Patrones regionales: una tipo- logía de los Centro de Gobierno}

La configuración del CdG no es un proceso inmutable, sino que evoluciona en el tiempo para adaptarse a las necesidades específicas de cada país. De este modo, es posible identificar comportamientos organizacionales comunes, entre los cuales destacan

\footnotetext{
${ }^{18}$ La salida de Filizzola se generó producto de desavenencias con el proyecto político del presidente. Posteriormente, el cargo sería ocupado por Federico Acuña, un reconocido policía con altos estudios a su haber. Sin embargo, debido a problemas de salud, la cartería finalizaría siendo presidida por Carlos Filizzola, militante del Partido País Solidario.
} 
el grado de centralización institucional y la especialización funcional del CdG. En virtud de los datos analizados, se clasifican el CdG en tres modelos de organización institucional, identificando subgrupos de países que comparten patrones comunes al interior de América Latina.

La formalización del proceso de toma de decisiones y la adaptabilidad institucional se vuelven elementos diferenciadores en cada uno de los diseños presentados. Igualmente, es posible identificar necesidades políticas y particularidades contextuales que generan efectos exógenos sobre el diseño del $\mathrm{CdG}$, manifestados en el nivel de estabilidad y en las estrategias de politización.

\section{Tipología $N^{\circ} 1$ : El Centro de Gobierno Institucionalizado}

\section{Antecedentes del Modelo Institucionalizado}

La primera clasificación corresponde a las experiencias que han logrado un alto nivel de formalidad institucional durante la configuración de sus CdG. Debido a la complejidad estructural, sus presidencias poseen amplias diferencias organizacionales. No obstante, contienen características que las convierten en casos singulares, diferenciándose de otras trayectorias a nivel regional.

Los diseños institucionales de Brasil y México pertenecen a $\mathrm{CdG}$ institucionalizados. La principal característica que devela la formalidad estructural es la combinación entre baja centralización y una alta especialización. Estos elementos permiten la desconcentración de funciones del $\mathrm{CdG}$, generando una división de trabajo que facilita la especialización estructural de las instituciones.

\section{Organización Institucional}

El Centro de Gobierno Brasilero se encuentra organizado por una Casa Civil que refleja la alta especialización funcional. La presencia de una amplia red de Subjefaturas ${ }^{19}$ alrededor de la presidencia devela la sectorialización de funciones en cada una de las etapas del proceso de formulación de políticas. Junto a esto, la complejidad institucional queda plasmada en la descentralización ejercida por los Ministerios de Planificación y Hacienda, lo cual permite un mayor grado de autonomía sobre el proceso decisional desarrollado en el círculo presidencial. De

\footnotetext{
${ }^{19} \mathrm{El}$ organigrama del Poder Ejecutivo Brasileño refleja la complejidad institucional del CdG. Asimismo, la atomización estructural devela el alto nivel de especialización para el desarrollo de funciones gubernamentales.
}

este modo, el entramado institucional cuenta con un alto grado de memoria institucional producto de la continuidad institucional.

El Centro de Gobierno Mexicano actúa sobre la base de una Oficina Presidencial [OPP] que sustenta las principales funciones básicas del CdG. La amplia gama de secretarías internas refleja la especialización sectorializada para labores de formulación de políticas públicas. (Lajous, 2000). Adicionalmente, la organización institucional posee estructuras que descentralizan el proceso decisorio, este es el caso de la Secretaría de Gobernación y la Secretaría de Hacienda (Flores y R., 2007).

\section{Composición Institucional}

En el caso de Brasil, los cargos más influyentes del CdG fueron asignados a militantes del PT, PMDB e independientes de perfil técnico. La combinación de criterios fue un elemento central para mantener la estabilidad del CdG brasileño. De esta forma, mediante una politización moderada, Rousseff fue capaz de estrechar los vínculos con su coalición y tecnificar el proceso decisorio mediante actores cercanos a la presidenta.

El CdG mexicano se conformó mediante un criterio similar, conjugando aspectos técnicos y partidarios para la selección de los principales cargos del CdG. La nominación de militantes del [PAN] e Independientes de alta experiencia técnica permitió el desarrollo de un CdG cercano al presidente. Sin embargo, con el transcurso de los años las instituciones comenzaron a politizarse, concentrando un gran número de panistas en los puestos centrales del CdG institucional.

En efecto, ambos países incurrieron en estrategias de politización moderadas, usando criterios técnicos y políticos. Sin embargo, la principal diferenciación se encuentra en la estabilidad interna de cada CdG. En consecuencia, la estabilidad puede ser causada por incidencias de carácter externo e interno (Gómez, 2012). Este aspecto es esencial para comprender las diferencias entre los subgrupos de países analizados.

\section{Incidencias del sistema político}

Para efectos del Centro de Gobierno Institucionalizado, el federalismo es un elemento contextual que actúa como condición suficiente pero no necesaria. De este modo, el sistema federado incide sobre las instituciones formales del $\mathrm{CdG}$, generando diseños que acentúan la descentralización de fun- 
Tabla 2: Tipología en diseños de Centros de Gobierno en América Latina

\begin{tabular}{lll}
\hline Subgrupo & $\begin{array}{l}\text { Tipología } \\
\text { Institucional }\end{array}$ & Características Centrales \\
\hline $\begin{array}{l}\text { Brasil } \\
\text { México }\end{array}$ & $\begin{array}{l}\text { Centros de Gobiemo } \\
\text { Institucionalizado }\end{array}$ & $\begin{array}{l}\text { Experiencias que han logrado un alto nivel de formalidad institucional, } \\
\text { conjugando una baja centralidad y altos niveles de especialización en las } \\
\text { funciones básicas del Centro de Gobierno. }\end{array}$ \\
\hline $\begin{array}{l}\text { Chile } \\
\text { Costa Rica } \\
\text { El Salvador }\end{array}$ & $\begin{array}{l}\text { Centros de Gobiemo } \\
\text { Institucionalizados }\end{array}$ & $\begin{array}{l}\text { Este tipo de diseños posee menor formalidad institucional, conjugando una alta } \\
\text { centralidad y un bajo nivel de especialización funcional. Una de las } \\
\text { características centrales es la flexibilidad para personalizar el diseño institucional. }\end{array}$ \\
\hline $\begin{array}{l}\text { Argentina } \\
\text { Ecuador } \\
\text { Paraguay }\end{array}$ & $\begin{array}{l}\text { Centros de Gobiemo } \\
\text { Mixtos }\end{array}$ & $\begin{array}{l}\text { Experiencias con diversos niveles de formalidad institucional, lo cual genera una } \\
\text { indefinición de su comportamiento institucional. Este diseño tiende a la } \\
\text { inestabilidad y sus instituciones pueden abarcar elementos de los otros modelos. }\end{array}$ \\
\hline
\end{tabular}

Fuente: Elaboración propia

ciones básicas ${ }^{20}$. Por otra parte, la continuidad del oficialismo no incide en la memoria institucional de las estructuras. Pese a que el [PAN] de México y el $[\mathrm{PT}]$ en Brasil han logrado continuar en el poder, la memoria institucional se desarrolla en función de un grupo de instituciones bases.

La minoría parlamentaria del PAN y su dificultad para formar alianzas con otros partidos refleja la inestabilidad asociada a la composición institucional del CdG. Este escenario es distinto en Brasil, ya que la presencia de una coalición con mayoría parlamentaria ha contribuido a la estabilidad del CdG institucional.

\section{Tipología N²: El Centro de Gobierno Semi Institucionalizado}

\section{Antecedentes del Modelo Semi Instituciona- lizado}

El escenario regional exhibe otro tipo de CdG caracterizado por estructuras con un menor nivel de institucionalización. Estas experiencias se constituyen sobre la base de estructuras semi formales, lo cual contribuye a flexibilizar el diseño del CdG antes de iniciar un período presidencial. El primer mandatario logra mayor arbitrariedad en la configuración del CdG, fenómeno que permite personalizar el diseño estructural, recurriendo a instancias informales durante el proceso decisorio.

En este marco, las experiencias institucionales más próximas a la semi formalidad son representadas por Chile, Costa Rica y El Salvador. Todos los países se caracterizan por la presencia de CdG fuertemente centralizados y un bajo nivel de espe-

\footnotetext{
${ }^{20} \mathrm{El}$ caso de Argentina devela la condicionalidad del federalismo, ya que pese a estar presente en el sistema político, las instituciones informales acentúan la centralización del proceso decisorio, generando un balance que matiza los efectos.
}

cialización. Estos elementos generan un control discrecional del diseño estructural y una reducción de la atomización institucional, lo cual implica que las instituciones partícipes del CdG no están especializadas funcionalmente.

\section{Organización Institucional}

En el caso de Chile, el staff de asesoría denominado Segundo Piso refleja el uso de estructuras no institucionalizadas como eje central del proceso decisorio. La informalidad estructural permite personalizar la configuración del $\mathrm{CdG}$, generando una coexistencia entre instituciones formales como la SEGPRES y un staff personal de asesoría inmediata. Por lo tanto, los presidentes de Chile cuentan con amplios recursos para la configuración del $\mathrm{CdG}$, permitiendo un mayor nivel de proximidad institucional entre las estructuras y el presidente.

En el caso costarricense, el CdG reúne elementos que disminuyen la formalidad de sus instituciones durante el proceso decisorio. Este es el caso del staff de asesoría privada y el grupo de expertos permanentes. Ambas instancias poseen elementos informales que permiten la configuración de un CdG más centrado en el presidente, generando un entorno institucional de confianza. Una de las ventajas de este modelo es el aumento de las fuentes de información para la toma de decisiones presidenciales.

Por último, la organización institucional salvadoreña está conformada por un CdG con instancias informales para la toma de decisiones. El diseño elaborado por Funes cuenta con un staff privado que cumple el rol de asesoría presidencial. Sin embargo, la centralidad del CdG radica en la amplia cantidad de secretarías posicionadas en la presidencia, lo cual evita la desconcentración del proceso decisorio. De este modo, la Secretaría Técnica, Secretaría de Asuntos Estratégicos y Secretaría de Comunicación se transforman en la base de un CdG centralizado. 


\section{Composición Institucional}

El Centro de Gobierno chileno se caracterizó por una composición basada en criterios técnicos y políticos. De esta forma, la designación de militantes [UDI] y $[\mathrm{RN}]$ permitiría mantener el nexo político entre el presidente y su coalición de gobierno. Por otra parte, los niveles de politización serían matizados por una alta designación de actores ligados a la tecnocracia y al mundo académico (Fernández y Rivera, 2012). De este modo, el CdG enfrentó una estabilidad moderada, logrando disminuir las rotaciones ministeriales en la medida que aumentaba la politización institucional del CdG.

Igualmente, Costa Rica favoreció la utilización de criterios partidistas, generando una estrategia de politización moderada. La gran cantidad de militantes [PLN] contribuiría al fortalecimiento de los lazos con el partido oficialista. Asimismo, la politización adquiere rasgos moderados debido a la integración de actores independientes [IND] y militantes del PUC, estrategia utilizada para la sostenibilidad de coaliciones. En consecuencia, la composición interna del $\mathrm{CdG}$ costarricense recurrió a una estrategia de coalición, lo cual permitió controlar la rotación inicial y logrando estabilizar el CdG al finalizar el período de gobierno analizado.

En el caso salvadoreño, el CdG se conformó en función de una baja politización, ya que exceptuando una institución, todas estuvieron lideradas por actores con un alto perfil tecnocrático, académico y provenientes del sector privado. Paralelamente, el nivel de estabilidad institucional del $\mathrm{CdG}$ es alto. Este fenómeno se encuentra relacionado al diseño del CdG salvadoreño, el cual posee una gran cantidad de secretarías, las que responden directamente al presidente.

\section{Incidencias del sistema político}

Un elemento contextual común para este tipo de CdG es la ausencia de un contingente legislativo capaz de asegurar mayorías parlamentarias, aspecto que en el largo plazo incide en la composición inestable del CdG. Asimismo, los tres países contaron con la presencia de coaliciones políticas, fenómeno que incide en la estrategia de politización utilizada por Chile y Costa Rica. Paralelamente, la singularidad de El Salvador se refleja en la baja politización, la cual no se ve reflejada en las secretarías del CdG, no así en el alto nivel de rotación ministerial desarrollado por el gabinete en su conjunto.

Por otra parte, la continuidad del oficialismo no es un elemento contextual que incida en la memoria institucional de este tipo de diseño CdG. Produc- to de la amplia cantidad de rasgos semi formales, el personalismo y la flexibilidad se sobreponen a la rigidez estructural característica de Centros de Gobierno con alta memoria institucional. Por lo tanto, la llegada al poder de los partidos [RN] en Chile y el [FMLN] en el Salvador no difiere del diseño institucional desarrollado por el PLN en Costa Rica, el cual ha logrado continuidad desde el año 2006.

\section{Tipología Nº3: El Centro de Gobierno Mixto}

\section{Antecedentes del Modelo Semi Instituciona- lizado}

Se identificó una tercera clasificación con diversos niveles de formalidad institucional. El CdG se encuentra en etapa de desarrollo, lo cual devela una indefinición estructural. Una de los rasgos principales es la creación de nuevas estructuras durante la gestión presidencial, lo que termina por complejizar la construcción institucional del CdG, convirtiéndolo en un diseño híbrido, compuesto por estructuras mixtas.

El diseño estructural de Argentina, Ecuador y Paraguay pertenecen a CdG mixtos. La principal característica que devela la hibridez del modelo es la coexistencia de instituciones centralizadas y una red de estructuras diseñadas para desconcentrar el proceso decisorio, provocando matices institucionales arraigados en la configuración del CdG. Consecuentemente, el nivel de especialización se encuentra en un rango intermedio debido a la amplia atomización del modelo. Sin embargo, producto de la indeterminación, muchas de las estructuras terminan perdiendo relevancia y otras llegan a ser reemplazadas por la creación de nuevas instituciones.

\section{Organización Institucional}

El caso de Ecuador es un claro ejemplo de adecuación estructural. Durante el período analizado, Rafael Correa diseñó un CdG compuesto por un despacho presidencial ${ }^{21}$, una red de Ministerios Coordinadores y un conjunto de secretarías altamente influyentes durante el proceso decisorio. De esta forma, mientras los ministerios coordinadores se encargaban de la descentralización de funciones inherentes al CdG, secretarías como SENAPLADES se encargó de centralizar las acciones presidenciales, respondiendo directamente al presidente.

\footnotetext{
${ }^{21} \mathrm{El}$ despacho presidencial está compuesto por un conjunto de oficinas informales que configuran un staff de asesoría privada, lo cual se convierte en un rasgo central del CdG semi institucionalizado.
} 
Por otra parte, la desaparición del Ministerio Coordinador de la política y la escasa participación de la Secretaría Presidencial en labores de CdG corrobora la indefinición estructural de la Presidencia.

De forma similar, el CdG diseñado por Cristina Fernández posee características que lo convierten en una estructura mixta. Por una parte, el CdG gira en torno a la Jefatura del Gabinete Ministerial, institucionalidad fundamental para la descentralización del proceso decisorio. Sin embargo, la Secretaría General de la Presidencia y la reciente creación de dos Oficinas Coordinadoras diseñadas para formalizar la asesoría personal han presionado hacia la centralización del sistema. De esta forma, la complejidad estructural revela la hibridez del $\mathrm{CdG}$, lo que ha permitido una mayor especialización funcional en la búsqueda de un modelo con instituciones bases.

A diferencia de Ecuador y Argentina, el CdG diseñado por Fernando Lugo posee un alto grado de centralidad. Sin embargo, la estrategia utilizada para fortalecer el control del proceso decisorio fue la creación de una nueva estructura funcional. De este modo, la reestructuración del Gabinete Civil permitiría disminuir los matices institucionales del CdG paraguayo. En consecuencia, pese a la centralidad estructural, el CdG está en plena etapa de desarrollo, volviéndose hibrido debido a las constantes trasformaciones experimentadas en un corto período de tiempo

\section{Composición Institucional}

En lo que respecta a composición interna, Ecuador y Argentina se caracterizaron por el diseño de CdG con altos niveles de politización, lo cual implicó la utilización de un único criterio político, la asignación de militantes del oficialismo. En este contexto, Ecuador concentró una gran cantidad de integrantes de Alianza PAÍS, los cuales además de pertenecer al movimiento, fueron cercanos al presidente. Por otra parte, Argentina desarrollo el mismo proceso mediante militantes del PJ, lo cual implicó la configuración de un CdG con amplia experiencia política.

Sin embargo, un común denominador de los países analizados es la alta inestabilidad estructural del CdG. En este marco, las estrategias de polarización extrema inciden en la desestabilización institucional del CdG. El desincentivo de integrar partidos aliados se convierte en un elemento que incide en el desgaste de los vínculos para la formación de coaliciones políticas. Por otra parte, el caso de Paraguay representa el extremo opuesto ya que la politización sería mínima, generando un $\mathrm{CdG}$ alta- mente independiente, lo cual provocaría altos costos de transacción durante el proceso de elaboración de políticas.

\section{Incidencias del sistema político}

Los CdG analizados en este subgrupo de países se caracterizan por tener presidentes con estilos altamente confrontacionales. Esto es central para comprender los rasgos de inestabilidad institucional. La tensión constante entre el CdG y el poder legislativo son elementos que inciden en la inestabilidad institucional de Argentina y Ecuador. Por otra parte, ambos países poseen mayorías en el Congreso, lo cual acentúa la confrontación durante el proceso de toma de decisiones. Finalmente, el caso paraguayo se convierte en una particularidad, ya que teniendo minoría en ambas cámaras, se genera una atmosfera confrontacional que impide la consolidación de alianzas políticas.

Por último, la continuidad política es un elemento que incide la estabilización del CdG, ya que al poseer diseños mixtos, la temporalidad de los gobiernos permite ajustar el diseño institucional desarrollado por estos países. De este modo, la reorganización del CdG en Ecuador y Argentina ha logrado mayor estabilidad desde la reelección política de Cristina Fernández y Rafael Correa.

\section{Etapas de Transición del Centro de Gobierno latinoamericano}

En términos generales, el CdG regional se diferencia por el nivel de institucionalización, fenómeno que acentúa o disminuye la especialización y formalización estructural del proceso decisional. De este modo, el CdG Institucionalizado permite la complejización de las estructuras, generando una mayor especialización funcional y una reducción de la discrecionalidad durante la elaboración de políticas públicas. Por otra parte, el diseño semi institucionalizado se caracteriza por un alto grado de flexibilidad estructural, lo que permite centralizar el proceso decisorio, reduciendo la especificidad funcional a cambio de una mayor personalización estructural.

Esta dicotomía estructural ha generado una discusión académica protagonizada por la presencia de posturas adversas. Por un lado, existen autores que abalan la flexibilidad y adaptabilidad del $\mathrm{CdG}$, priorizando la presencia de estructuras semi formales como staff de asesoría privada, grupo de expertos y comités políticos. Paralelamente, existen argumentos ligados a la necesidad de institucionalizar la presidencia, estos sostienen la oportunidad 
de ampliar la red de estructuras especializadas en las labores básicas del Centro de Gobierno institucional (Lahera, 2005).

\section{Conclusiones y recomendacio- nes}

\section{Conclusiones}

La configuración estructural del CdG es un espacio que prevalece a lo largo del tiempo, generando un soporte institucional integrado por instituciones básicas (Moe y Howell, 1999). Esta característica se encuentra presente en todos los países analizados, ya que independientemente de la reorganización que experimente el $\mathrm{CdG}$, existen instituciones como el Ministerio de Hacienda o las Secretarías Presidenciales que actúan como soporte central para dar forma a un Centro de Gobierno institucional.

El diseño institucional del CdG latinoamericano es una causa, y al mismo tiempo, un efecto de determinados elementos circunstanciales. El CdG es capaz de incidir en el proceso de elaboración de políticas, convirtiéndose en un efecto mediante el desarrollo de sus funciones básicas, generando un aumento [o disminución] de la capacidad de gobierno, lo cual fundamenta el interés por su fortalecimiento. Igualmente, el $\mathrm{CdG}$ es una causa de factores que confluyen a través de una lógica de incidencia externa e interna.

De este modo, la reorganización del CdG puede ser influenciada por factores exógenos provenientes del sistema político. Este es el caso de sistemas de partidos dividido, presencia de coaliciones y mayorías parlamentarias, son características centrales para determinar los criterios que darán paso a la composición del Centro de Gobierno latinoamericano. Igualmente, existen factores endógenos que inciden en la organización institucional del $\mathrm{CdG}$, tales como el grado de centralización del proceso decisorio y la especialización funcional de las actividades básicas del CdG. Estos aspectos tienen una clara incidencia en el comportamiento organizacional de la presidencia.

Al momento de responder ¿Qué factores inciden en el diseño institucional del CdG en América Latina?, es posible argumentar la inexistencia de un único modelo institucional que represente el diseño del CdG latinoamericano (BID, 2013a). No obstante, existen rasgos comunes que se repiten en distintos subconjuntos de países, lo cual genera comportamientos organizacionales similares (Scartascini y Tommasi, 2012; Sulbrandt, 1994). Los principales elementos definitorios fueron la centralización del diseño institucional y la institucionalización de las funciones básicas del CdG (Moe y Caldwell, 1994). Ambos elementos corroboran la presencia de patrones regionales, los cuales están presentes pese a las diferencias institucionales que caracterizan la organización del CdG en América Latina (BID, 2013b).

Los distintos CdG latinoamericanos son comparables debido a la base institucional que posee en cada uno de los países analizados (Moe y Howell, 1999). Por lo cual, la reorganización del CdG encuentra explicaciones teóricas fundamentadas en el neo institucionalismo ${ }^{22}$, lo cual permite analizar el CdG desde el comportamiento organizacional o a través del nivel de formalidad vinculado a la claridad de las reglas del juego (Burke, 2000).

No obstante, centrarse únicamente en las instituciones formales impide analizar la otra cara de la institucionalización, la de la presidencia informal, a veces no tan visible pero de gran relevancia (Rockman, 1987). Por lo cual, quedan muchas preguntas por resolver respecto a la incidencia que adquieren las estructuras informales en el proceso de toma de decisiones, fenómeno que abre nuevas líneas de investigación a través de la reexaminación del diseño institucional del CdG en Latinoamérica. De este modo, por muy sólido y permanente que parezca un Centro de Gobierno, existen diversos códigos de conducta, normas de comportamiento o simplemente convenciones que rompen los esquemas formales analizados en esta investigación (Gómez, 2012).

La periodicidad de regímenes autoritarios y la longevidad de las constituciones no son patrones regionales que incidan en el diseño estructural del CdG. Asimismo, la amplitud de los poderes presidenciales es divergente en todos los escenarios, lo cual acentúa la diferenciación histórica e institucional en cada uno de los países analizados.

El análisis del sistema político contemporáneo devela características comunes que se convierten en elementos exógenos que incentivan la centralización y la especialización institucional del CdG latinoamericano. El diseño estructural desarrollado por el presidente es influenciado por factores contextuales tales como el contingente legislativo del jefe de gobierno, la capacidad de formar coaliciones políticas y la continuidad del oficialismo en la presidencia (Méndez, 2007; Arana, 2012). En suma, existen características del sistema político que inciden en la configuración del $\mathrm{CdG}$, promoviendo estrategias

\footnotetext{
${ }^{22}$ Las categorías analíticas desarrolladas por Moe (1999) contribuyeron sustancialmente al análisis institucional del Centro de Gobierno Latinoamericano. De este modo, proveniente del neo institucionalismo, la "política de elección estructural" se convierte en un modelo teórico aplicable a cualquier presidencia institucional.
} 
que coadyuvan a la estabilidad y politización interna.

Existen dos estrategias que inciden en el comportamiento organizacional del entramado final, esas son la centralización institucional y el grado de especialización funcional (Moe y Howell, 1999; C. y Hult, 1995). Ambas estrategias responden al modelo de política de elección estructural desarrollado por Moe y Howell (1999), el cual busca generar una adecuación estructural capaz de originar un diseño institucional congruente con los incentivos y el contexto situacional. De esta forma, el análisis de países permite corroborar la capacidad presidencial para elegir las estructuras más plausibles durante la configuración del CdG. Sin embargo, el alcance de la investigación no permite distinguir las estructuras más influyentes durante el proceso decisorio, lo cual abre paso a nuevos frentes de investigación.

En consecuencia, el presidente se transforma en el único actor del $\mathrm{CdG}$ con incentivos para seleccionar las estructuras del CdG que permitirán desarrollar un gobierno efectivo y un mayor grado de autonomía (Moe y Caldwell, 1994). En este marco, la politización se convierte en el eje central para la configuración interna del CdG. De acuerdo a los resultados del estudio, una estrategia de politización que integre al partido oficialista y a ciertos aliados circunstanciales es fundamental para la estabilidad del CdG. Asimismo, la politización extrema acentúa los conflictos, generando escenarios que constriñen el proceso decisorio presidencial.

En conclusión, no existe un modelo óptimo para el desarrollo de las funciones básicas del Centro de Gobierno, ya que tanto los diseños institucionalizados como los semi institucionalizados poseen características que contribuyen al proceso de elaboración de políticas. Por ende, ambos modelos se convierten en alternativas fiables. Por otra parte, la presencia de un modelo mixto refleja la transición experimentada por algunos países respecto a la reorganización definitiva del CdG. Por lo cual, sus instituciones se articulan sin una estrategia específica, generando una inestabilidad que implica nuevos procesos de reorganización institucional.

\section{Recomendaciones de reforma al Cen- tro de Gobierno en Latinoamérica}

Actualmente, existen estudios que argumentan la necesidad de fortalecer el acervo de técnicas, métodos y habilidades que permitan conjugar una relación integral entre el presidente y su equipo de gobierno (Babino, 2008). En efecto, una de las propuestas de esta investigación es preocuparse por la composición del CdG. Para esto es necesario ma- tizar los efectos generados por la politización. En otras palabras, la combinación de criterios técnicos, políticos y de coalición podría contribuir a generar un mayor grado de estabilidad institucional. De esta forma, las funciones básicas del CdG serían lideradas con menor interrupción, permitiendo que los actores asignados logren continuidad durante el proceso decisional.

En segunda instancia, esta investigación identifica altos déficit en funciones básicas del CdG asociadas a la implementación de políticas públicas, aspecto que genera brechas entre lo programado y lo ejecutado (Cavarozzi, 2013; BID, 2013a). Por lo cual, este estudio propone fortalecer funciones que van desde el monitoreo de desempeño hasta la coordinación gubernamental. Para esto, resulta imprescindible proponer el desarrollo de un mayor nivel de especialización funcional, aspecto central para la sectorialización de actividades, tecnificando procedimientos para aumentar la calidad de la ejecución. En síntesis, el aumento de especialización en funciones básicas del CdG contribuye al fortalecimiento del proceso de implementación, conjugando procesos de tecnicidad y calidad durante la acción gubernamental.

Finalmente, este capítulo sostiene la necesidad de fortalecer la memoria institucional del $\mathrm{CdG}$ en Latinoamérica. Los hallazgos de esta investigación develan que una mayor capacidad de memoria fortalece la continuidad y especialización técnica del Centro de Gobierno Institucional. Por lo tanto, en la medida que el CdG posee un diseño básico con estructuras continuas, es posible desarrollar mayor memoria institucional, lo cual incide en el proceso de elaboración de políticas públicas. Sin embargo, cabe señalar que el principal obstáculo de esta categoría es la constante reorganización institucional, fenómeno recurrente en los países de América Latina.

\section{Referencias}

Acuña, C. C. (2007). Lecturas sobre el Estado y las políticas pú'blicas. Buenos Aires: Proyecto de Modernización del Estado.

Acuña, C. C. (2013). ¿Cuanto importan las instituciones?: gobierno estado y actores en la política argentina. Siglo XXI.

Aguilar, L. C. (2009). Política Pública. Siglo XXI.

Arana, I. (2012). ¿quién le susurra al presidente: Asesores vs Ministros en América Latina. Revista Política, 50:33-61.

Babino, L. (2008). La Oficina del Gobernante: 
aportes para fortalecer los procesos de conducción política de las organizaciones pú'blicas. Revista Reforma y Democracia, 43:1-11.

BID (2006). La política de las políticas públicas. BID, Washington D. C.

BID (2013a). El fortalecimiento del Centro de Gobierno en América Latina y el Caribe. BID.

BID (2013b). The role of the Center of Government: A literature rewiev. BID.

Boeninger, E. (2007). Políticas públicas en democracia: Institucionalidad y experiencia chilena 1990 - 2006. Uqbar, Santiago.

Bonvecchi, A. (2010). Tipos de Presidencialismo y efectividad del control legislativo sobre el presupuesto: control político y control técnico en Argentina. Brasil y México, 1:66-80.

C., W. y Hult, K. (1995). Governing the White House from Hoover to LBJ. University Press of Kansas.

Cavarozzi, M. (2013). Modelos de acción presidencial en el Siglo XXI latinoamericano. Revista del CLAD Reforma y Democracia, 55:1-10.

Cheibub, A. y Limongi, F. (2008). Instituciones políticas y gobernabilidad: el desempeño del gobierno y apoyo legislativo en la democracia brasileña. Ed. Salamanca.

Coutinho, M. (2008). Un análisis institucional de la organización de la Presidencia en Argentina. Revista Colección, 18-19:17-47.

Crozier, M. (1984). No se cambia la sociedad por decreto. Instituto Nacional de Administración Pú'blica (INAP).

Dávila, M. (2010). Tecnocracia y democracia en Chile contemporáneo: el caso de los gobiernos de la Concertación (1990-2010). Revista Sociológica, 24:199-217.

Echebarría, K. (2006). Caracterización empírica de las burocracias: configuración y roles en el proceso de elaboración de políticas pú'blicas. Revista Reforma y Democracia CLAD, 34:1-11.

Edwards, G. (2003). On deaf ears. The limits of the bully pulpit. Yale University Press, New Haven, Ct.

Egaña, R. (2002). Reforma y modernización del Estado en Chile: avances y desafíos. CEP.

Egaña, R. y Chateau, J. (2011). El centro de gobierno: lecciones de la experiencia chilena durante los gobiernos de la concertación (1990 2010). Revista Chilena de Administración Pública, 17:137-191.
Fernández, M. y Rivera, E. (2012). La Trastienda del Gobierno: el eslabón perdido en la modernización del Estado Chileno. Catalonia, Santiago de Chile.

Flores, J. y R. (2007). El Staff Presidencial en México. UNAM, México D.F.

Freidenberg, F. (2012). Ecuador 2011: Revolución ciudadana, estabilidad presidencial y personalismo político. Revista Ciencia Política, 32:129150 .

Gómez, A. (2012). Más allá de la teoría de la consolidación: dimensiones problemáticas de las instituciones en nuevas democracias. Revista Espiral, 54:109-140.

Gómez, S. y Villareal, E. (2013). Costa Rica: La derrota prematura de un gobierno dividido. Revista Ciencia Política, 33:117-134.

Greeinstein, F. (1997). El Impacto de la personalidad en el liderazgo presidencial norteamericano. Revista Psicología Política, 15:7-15.

Johnson, R. (1974). Managing the White House. Harper y Row, New York.

Krause, G. y Cohen, J. (2000). Oportunity, constraints, and the development of the institutional presidency: The issuance of executive orders, 1939 - 96. The Journal of Politics, 62:88-114.

Lahera, E. (2005). Implementación de las políticas y asesoría presidencial. X Congreso Internacional del CLAD sobre la Reforma del Estado y de la Administración Pú'blica, Santiago.

Lajous, L. (2000). Presidente y Congreso: Propuesta para un mejor entendimiento. Cambridge: Weatherhead Center for International Affair.

Lanzaro, J. C. (2003). Tipos de Presidencialismo y coaliciones en América Latina. CLACSO.

López, M. (2010). La democracia en paraguay: un breve repaso sobre los partidos tradicionales, el sistema electoral y el triunfo de fernando lugo méndez. Revista Enfoques, 13:89-106.

Lowi, T. (1993). El Presidente Personal: Facultad otorgada, promesa no cumplida. FCE, México D.F.

Martínez Nogueira, R. (2013). La presidencia y organizaciones estatales como constructoras de institucionalidad en la argentina. En Acuña, C., editor, ¿Cuanto importan las instituciones?: gobierno estado y actores en la política argentina. Siglo XXI, Buenos Aires.

Matus, C. (2007). Teoría del Juego Social. Universidad de Lanú's. 
Méndez, J. (2007). La Oficina Presidencial y el Liderazgo político en México y Estados Unidos: ¿Incertidumbre competitiva o certidumbre cooperativa? Revista Foro Internacional, 47:839867.

Mintzberg, H. (1982). La necesidad de coherencia en el diseño de la organización. Harvard Business Review, 83.(3):66-83.

Moe, T. (1990). Political Institutions: The neglected Side of the Story. Journal of Law, Economics and Organization, 6:213-253.

Moe, T. (1999). The politicized Presidency. En Pfiffner, J., editor, The Managerial Presidency. Texas AyM University, Texas.

Moe, T. y Caldwell, M. (1994). Institutional foundations of democratic government. Journal of Institutions and Theoretical Economics, 150:171195.

Moe, T. y Howell, W. (1999). Unilateral action and presidential power: A theory. Presidential Studies Quarterly, 29:850-873.

Muñoz, J. (2012). Configuración organizativa de los Centros de Gobierno: Los casos de Alemania y Ecuador. Tercer Encuentro Anual de Sociedad Chilena de Políticas Pú'blicas.

Negretto, G. (2006). Minority presidents and democratic performance in latin america. Latin American Politics y Society, 48:63-92.

Neustadt, R. (1990). Presidential Power and the modern Presidents. Free Press.

OCDE (1998). Managment Challenges at the Centre of Government: Coalition Situation and Government transitions. Documento SIGMA 22, Paris, OCDE.

Pachano, S. (2010). Ecuador: El nuevo sistema político en funcionamiento. Revista Ciencia Política, 30:297-317.
Peters, G. (1998). Comparative Politics. New York University Press, New York.

Peters, G. (2003). El Nuevo institucionalismo: la teoría institucional en la Ciencia Política. Gedisa, Barcelona.

Pfiffner, J. (2009). The contemporary presidency: Decision making in the bush white office. Presidential Studies Quarterly, 39:363-384.

Rehren, A. (1993). La presidencia en el gobierno de la Concertación. Revista Estudios Sociales, $75: 15$.

Rehren, A. (1998). La organización de la Presidencia y el Proceso Político Chileno. Revista Ciencia Política, XIX:89-124.

Reverse, R. (2009). Las elecciones de 2009 en el Salvador: avance y retos de la democracia. Revista Nueva Sociedad, 224:4-17.

Rockman, B. (1987). Reforming the Presidency: Nonproblems and problems. Political Science and Politics, 20.

Rosales, M. y Calvo, S. (2010). Los partidos políticos brasileños y las elecciones 2010. Grupo de Estudios internacionales contemporáneos (GEIC), pp. 1-21.

Scartascini, C. y Tommasi, M. (2012). Institucionalización de las instituciones políticas y su impacto sobre las políticas públicas. Documento de trabajo IDB-WP-287: BID.

Sulbrandt, J. (1994). Presidencia y gobernabilidad en América Latina: de la presidencia autocrática a la democracia. Revista Reforma y Democracia, $2: 1-35$.

Von Bulow, M. y Lassance, A. (2012). Brasil después de lula: ¿más de lo mismo? Revista Ciencia Política, 32:49-64. 